\title{
REGULATORY EFFECTIVENESS: \\ THE IMPACT OF REGULATION AND REGULATORY \\ GOVERNANCE ARRANGEMENTS ON ELECTRICITY \\ INDUSTRY OUTCOMES
}

\author{
By \\ Jon Stern \\ (London Business School) \\ and \\ John Cubbin \\ (City University)
}

\begin{abstract}
The paper reviews a number of studies of the effectiveness of utility regulatory agency and governance arrangements for the electricity industry, particularly for developing countries. It discusses governance criteria and their measurement, both legal frameworks and surveys of regulatory practice. It also discusses the results from econometric studies of effectiveness for regulatory agencies in the electricity and telecommunications industries and compares these with the results from econometric studies of independent central banks and their governance. The paper concludes with a discussion of policy implications and also of priorities for information collection to improve understanding of these issues.
\end{abstract}

World Bank Policy Research Working Paper 3536, March 2005

The Policy Research Working Paper Series disseminates the findings of work in progress to encourage the exchange of ideas about development issues. An objective of the series is to get the findings out quickly, even if the presentations are less than fully polished. The papers carry the names of the authors and should be cited accordingly. The findings, interpretations, and conclusions expressed in this paper are entirely those of the authors. They do not necessarily represent the view of the World Bank, its Executive Directors, or the countries they represent. Policy Research Working Papers are available online at http://econ.worldbank.org. 


\section{Introduction}

The problem of low growth in infrastructure industry output and investment for developing and (to a lesser extent) transition economies (DTEs) is well-documented. Repeated studies have shown excess demand, low coverage outside major towns, low investment rates, poor quality, low maintenance and availability rates, etc. ${ }^{1}$ This has had a major impact on DTE growth rates. For instance, Calderon and Serven (2002) estimate that a $1 \%$ growth in power generation capacity per worker increases GDP growth by $0.09 \%$ and a $1 \%$ increase in phone lines per worker increases GDP growth by $0.19 \%$.

The problem is how to increase not only the rate of investment but also the productivity of those investments. The dominant model of provision (at least for electricity and telecoms) for most of the twentieth century was by vertically and horizontally integrated state-owned national monopolies. By the 1980s, particularly for electricity, it was becoming increasingly clear that this model was associated with low productivity and unnecessarily high capital-output ratios, associated - at least in OECD and Comecon countries - with large rates of high-cost investment.

Not surprisingly, virtually all developing countries adopted the dominant state-owned monopoly model for their infrastructure industries from the 1950s onward. This was partly because of the dominant ideology of the time and partly because of the influence and models of the colonial powers such as Britain and France as well as of Russia and central planning. The results of this model, however, became increasingly disappointing and from the 1980s there have been increasing moves toward greater use of private investment, privatization and competition in non-network elements - in developing as well as in developed countries. This arose for two main reasons:

(a) the growing demands on tax revenues that led governments to want to find alternative sources of funding for infrastructure industry investment programs together with the growing fiscal burden of subsidies and cross-subsidies; and

(b) the poor efficiency and expansion record with the need to introduce modern technologies and management practices that, in turn, required the introduction of commercial incentives to increase efficiency.

In DTEs, the recent trend toward commercialization and private investment in infrastructure investment ${ }^{2}$ started in Latin America (particularly Chile and Argentina) before spreading to Central and Eastern Europe after 1989 and - to a lesser extentAsia, the Commonwealth Independent States (CIS) and Africa in the 1990s. The mid-

This paper was prepared as part of the research program on Industrial Organization Policy for Development at the Development Research Group of the World Bank, under the direction of Ioannis Kessides. We are grateful for helpful comments on various aspects of this paper from seminar participants at the University of Cambridge and at City University. The authors alone are, however, solely responsible for the analysis and the views expressed which should not be attributed to the World Bank or any of its staff or members.

$1 \quad$ See Kessides (2004) for a comprehensive recent survey.

2 This was a revival of an old trend. A high proportion of nineteenth and early twentieth century infrastructure investment was privately financed, particularly in railways. See Stern (2003) for a discussion of UK experience. 
1990s saw a boom in these developments with major private investment flows into electricity and telecoms - at least for the larger middle income countries in Latin America and Asia.

According to the World Bank Private Participation in Infrastructure (PPI) Database, private investment in electricity (including privatization revenues) in DTEs rose from $\$ 1$ billion in 1992 to $\$ 18$ billion in 1995 and $\$ 44$ billion in 1997 . However, since 1998 - and particularly since 2000 - private investment flows, particularly foreign private investment flows, into DTE infrastructure industries have fallen sharply. For electricity, they have fallen back very sharply so that, since 1999, only in 2000 were flows to DTE countries as measured in the World Bank PPI Database (at \$25 billion) above the 1995 level. Between 2000 and 2001, they almost halved; and, between 2001 and 2002, they almost halved again. The 2002 level of private investment flows in electricity in DTEs, as measured in the World Bank PPI Database, was $\$ 5.5$ billion - lower than in any year since 1991.

As a result of the major and potentially sustained private investment downturn in electricity and other infrastructure industries, there has, in recent years, been growing scepticism about whether the new model, based on private investment and competition in non-natural monopoly segments, is appropriate in developing countries - even middle-income countries let alone low-income countries such as those in SubSaharan Africa. This scepticism seems to be shared by many capital market participants. $^{3}$

Regulation and regulatory governance have played a major role in this evolution of opinion. The optimism of the late 1980s and early 1990s that DTE electricity and other similar infrastructure industries could be commercialized and financed from private investment flows was heavily associated with a strongly optimistic view that viable and effective regulatory arrangements could readily be established in many if not all DTEs ${ }^{4}$. This optimistic view was reflected in the classic 1994 paper by Levy and Spiller.

However, the establishment of the new regulatory agencies, most established in the last 5-10 years, did not prevent the Asian IPP crisis, nor the collapse of energy regulatory arrangements in Argentina, nor similar difficulties in some other Latin American countries ${ }^{5}$. Further, the regulatory agencies in Argentina and elsewhere have not been used to help in a "work-out" and post-crisis transition or strengthened; rather, the regulatory agencies have been put into suspended animation and marginalized. Indeed, the weaknesses of the new regulatory agencies and their governance arrangements are often ascribed as an important contributory factor to the development of these crises ${ }^{6}$. In addition, the returns to the aid assistance used in establishing DTE regulators do not look encouraging.

$3 \quad$ See Lamech and Saeed (2003) and Standard \& Poor's (2000).

4 The establishment of independent regulatory agencies was seen as the typical route although alternative contract-based options also had their adherents.

5 Including the high renegotiation and failure rate of concession contracts as demonstrated in Guasch, Laffont and Straub (2003).

$6 \quad$ See Stern and Holder (1999), Estache (2002). 
This has led to a considerable rethink about the potential both for developing effective regulatory agencies in middle-income as well as low-income DTEs and to renewed scepticism about the potential for private investment in DTE infrastructure industries like electricity, including the potential for regulatory agencies to provide the necessary underpinnings. The reversal from the Levy and Spiller optimism may, however, primarily reflect over-optimistic expectations in the mid-1990s rather than the collapse of the 'private investment independent regulatory agency' infrastructure policy project.

Economic reform in Central and East European (CEE) and CIS economies has demonstrated clearly how hard it can be and how long it can take to create effective new economic agencies. The success of the post-1980s policy project now seems to depend on utility and regulatory reform across Latin America and Asia as well as in Africa and elsewhere.

This paper is intended to help address the question of whether the development of effective regulatory arrangements with good governance remains a sensible and viable strategy for encouraging investment and improvements in quality for infrastructure industries in DTEs in the more sceptical climate of the early twenty-first century. We concentrate on empirical studies and what can be established from them. However, we also draw where appropriate on the emerging literature on the role of institutions for economic growth and good policy to provide a context within which this question can reasonably be addressed ${ }^{7}$. Thus, the purpose of this paper is to summarize what we currently know about the effectiveness of regulatory agencies for electricity in developing countries and provide an extensive and detailed survey of the existing literature on the effectiveness of regulatory agencies and the importance of key governance criteria in DTEs--to set out what we can estimate about the effectiveness of current regulation and governance characteristics on the basis of currently available data so that the data needs (and collection methods) for future policy-directed research can be clearly identified.

Since most of the new (OECD as well as DTE) electricity regulators are relatively young, there is relatively little literature on measuring the impact of regulation and regulatory governance on investment, consumption growth, efficiency, etc. However, there is rather more both for telecoms - where privatization, liberalization and independent regulation not only started earlier but are also less difficult - and also for independent central banks. We draw on these areas in our literature review not least to help identify future data needs.

In this paper we cover the following issues:

- The specification of relevant (ex ante) governance criteria for utility regulators (Section 2).

7 See, for instance, Acemoglu, Johnson and Robinson (2000), Easterly and Levine (2002), Subramanian, Rodrik and Trebbi (2002) and Rodrik (2003). 
- The results of surveys of regulatory governance criteria (Section 3)--this covers both formal, legal governance criteria and surveys of how well DTE regulators operate in practice.

- The resources available to regulatory agencies in DTEs and how they compare with the demands on regulators (Section 4).

- Studies, particularly econometric studies, of the impact of regulatory effectiveness on regulatory outcomes (e.g. investment, electricity consumption growth, availability, losses) (Section 5)--this covers not only the recent (and small) literature on electricity, but also the larger and better established literature on the impact of regulation on telecom outcomes.

- Comparison with the literature on independent central bank (ICB) governance and tests of ICB effectiveness on macro-economic outcomes (Section 6).

The paper ends with a short section of conclusions and key points arising from the literature review (Section 7). 


\section{Ex Ante Governance Criteria for Utility Regulators}

There is an extensive literature on regulatory governance both in general and as it should be applied to utility regulation.

The modern literature on the latter effectively starts with the seminal 1994 paper by Levy and Spiller in which they emphasize the distinction between (a) regulatory governance arrangements and (b) regulatory content (ie what was regulated and how $)^{8}$. On regulatory governance, Levy and Spiller drew attention both to the need for governance arrangements that were sufficiently robust to provide adequate protection for private investors as well as consumers and were securely located in the economic, political, constitutional and legal arrangements of individual countries.

This view became (and remains) the dominant paradigm within which thinking about regulatory arrangements for electricity and other infrastructure industry has developed. However, since then the literature on governance has developed considerably both conceptually and empirically.

In this section, we consider what governance features have been considered most important for effective utility regulation.

\subsection{Levy and Spiller 1994}

Levy and Spiller (1994) define the governance structure as "the mechanisms that societies use to constrain regulatory discretion and to resolve conflicts that arise in relation to these constraints.",

Levy and Spiller do not, however, make substantive suggestions about the required nature of these mechanisms other than to emphasise the need for them to correspond to the institutional endowment of the countries in question. Indeed, they take the view that there may be a variety of types of regulatory arrangement that meet the requirements set out above and which will support private investment. This is shown in the following quotation from the introduction to their paper: "...we argue that performance can be satisfactory with a wide range of regulatory procedures as long as three complementary mechanisms restraining arbitrary administrative action are all in place: (a) substantive restraints on the discretion of the regulator, (b) formal or informal constraints on changing the regulatory system and (c) institutions that enforce the above formal - substantive or procedural - constraints" 10 .

In the empirical section of their paper (which concentrates on telecom regulation), Levy and Spiller concentrate on examining issues such as how easy or difficult it was in the five countries examined (a) to change primary legislation; (b) to change licences (or franchise/concession contract) terms; (c) the quality of the regulatory

$8 \quad$ The Levy and Spiller paper (and the regulatory governance-content distinction) drew directly on the work of Douglass North and the new institutional economics of Oliver Williamson.

9 See Levy and Spiller (1994), p 463. All page references are to the reprint of the original Journal of Law, Economics and Organisation article in the Oliver Williamson and Scott Masten 1999 book of reprinted papers 'The Economics of Transaction Costs'. See Levy and Spiller op cit, pp 461-2. 
bureaucracy; and (d) the reliability of the courts. These concerns arise not least because they see the fundamental problem for regulatory governance as restraining the degree of regulatory discretion. This leads to a scepticism about the value of independent utility regulators unless they have little or no discretion. This relative absence of discretion they suggested was the case for the Chilean telecom regulator and was a good model for other countries viz the regulation by contract in Jamaica where the regulator's job was merely to enforce the contract.

In practice, it is virtually impossible for regulatory agencies to avoid interpretation of their objectives and to avoid discretion. The issue then becomes how to establish governance procedures that allow for the inevitability and desirability of a non-trivial degree of bounded and accountable discretion ${ }^{11}$. In this context it is worth noting how the Jamaican telecom regulation by monopoly concession contract has now evolved into an increasingly liberalized and competitive industry overseen by a UK-style regulator with normal regulatory discretion but proper accountability ${ }^{12}$.

The issue of what are the key features of good regulatory governance is relatively unimportant for a tightly constrained regulatory agency with near zero discretion particularly if overseen by reliable, sound and speedy law courts. However, in practice, for regulators with significant discretion, the issue is crucial. In the latter case, strong and effective governance features (including sound and well-defined procedures) are essential as the only way so far discovered for providing bounds and accountability on regulatory decisions. Since zero or near-zero discretion for regulatory agencies is unavoidable in practice, it is the latter perspective that has implicitly or explicitly driven most of the post-Levy and Spiller discussions of the relevant criteria for effective regulatory governance.

\subsection{Regulatory Governance Criteria Since 1997: Warrick Smith, Stern \& Holder, Noll, etc.}

The key feature to note about regulatory governance criteria is that there is very strong agreement between the various authors as to what good governance entails. They all emphasize clarity of assignment of functions, regulatory autonomy, accountability and transparency.

In 1997, Warrick Smith had three highly influential pieces on utility regulation published as Notes in the World Bank series: "Public Policy for the Private Sector". These pieces clearly summarized a lot of the work and thinking that had been devoted to the issue inside the World Bank. On governance criteria, the most important was the piece on regulatory independence ${ }^{13}$. Looking back at this paper with 2003 lenses, its key points are the following:

- An acceptance of the inevitability of some degree of regulatory discretion (unlike Levy and Spiller);

\footnotetext{
$11 \quad$ See Stern and Trillas (2001) and Stern (2002) mimeo for a fuller discussion of the arguments in favour of the desirability of a significant degree of regulatory discretion - at least after any heavily constrained initial period.

12 See Stirton and Lodge (2003) for a detailed account.

13 See "Utility Regulators - The Independence Debate" Public Policy for the Private Sector Note No 127, The World Bank, Oct 1997.
} 
- An emphasis on organizational autonomy balanced by accountability;

- The need for a primary law to establish the mandate of the regulator;

- The need for secure funding e.g. from levies on regulated companies;

- The concern with appointment and dismissal conditions of regulator commissioners (or equivalent);

- The need for "rigorous transparency" with open decision making and publication of decisions with justification;

- The concern over paying regulatory staff the appropriate rate for the job and the need to avoid civil service pay scales;

- An awareness that regulatory practice can seriously fall short of the independence written into the law and secondary legislation;

- The suggestion of intermediate transitional models between implicit regulation by Ministers and explicit regulation by a regulatory agency.

Also in 1997, the UK Better Regulation Task Force (BRTF) published its Principles for Good Regulation ${ }^{14}$. Their five principles were (and remain):

$>$ Transparency

$>$ Accountability

$>$ Proportionality

$>$ Consistency

$>$ Targeting

Each of those five principles is associated by the BRTF with five sub-principles ${ }^{15}$. It is obvious that these principles are very similar to those in Smith (1997) listed above.

Also, in 1997, Jon Stern published a paper on regulatory independence in Business Strategy Review ${ }^{16}$. That paper is very similar in its perspective and in the choice of key governance attributes to the virtually contemporaneous Warrick Smith paper. The main difference is that Stern (1997) places a heavier emphasis on the notion of informal accountability - the understandings within the country on the custom and practice of regulation ie the "rules of the game".

One interesting similarity between Stern (1997) and W Smith (1997) is that they were both optimistic about the possibilities of interim or transitional regulators. On this issue, Stern's views have changed and he has become significantly more sceptical of the virtues of such 'stepping-stone' regulatory agencies like Ministry regulatory departments or advisory regulators. All too often, the interim regulator with little or no decision-making power is a substitute for a "real" regulator and the later steps are not taken. This is most obvious in Asian countries like Malaysia and Thailand but it also largely holds true for Central European countries - at least until the need to

14 The BRTF is responsible for advising the UK government on all aspects of regulation, not just economic regulation of utilities.

15 See Annex B of the Better Regulation Task Force report on economic regulators. These principles are also prominently displayed on the home page of the BRTF website (http://www.brtf.gov.uk)

'What Makes an Independent Regulator Independent?', Business Strategy Review, Volume 8, Issue 2, Summer 1997. 
incorporate European Union (EU) legislation forces changes for the EU Accession countries. $^{17}$

This issue has a wider importance in that Stern (1997) conjectured that different economic, cultural and political systems might produce different forms of regulator, including types not yet observed. In this case, we might observe a set of good alternatives to the standard model derived from US, UK and similar. If so, we should expect considerable variation in the institutional forms in which basic governance attributes (accountability, transparency, etc) were met - and successfully met. This is what one would also expect from higher level reasoning on the relationship between economic functions and institutional forms (eg North (1994), Rodrik (2003), etc). However, as yet, no alternative institutional or governance forms have emerged for utility regulation. Even for concession contracts in infrastructure, standard regulatory institutions with an external regulator and standard governance features appear significantly to improve performance. (See Guasch, Laffont and Straub (2002), Stern (2003), etc.)

A second interesting point is that both Stern (1997) and Smith (1997) concentrate on discussing regulatory independence as independence from government. They both implicitly assume independence from regulated companies and discuss this much less. However, the 1996 EU Electricity and Gas Directives concentrated on establishing independence from regulated companies (typically the state-owned monopoly incumbent). Only in the 2002 Directives has the EU defined independence to include independence from government. Given the history of regulation over the last 5 years, particularly in Latin America, maybe more attention should be given to the issue of the independence of the regulatory agency from the dominant utility companies.

The distinction between formal and informal accountability in Stern (1997) was further elaborated in Stern and Holder (1999). However, the empirical results reported in the latter are a summary of the main results of a 1998 NERA study of 13 Asian developing country infrastructure regulatory regimes for the Asian Development Bank. (The Stern-Holder paper also includes some additional analysis of general issues). We will discuss the results of the study for the ADB in a later section. The point to note here is that the governance criteria set out in Stern and Holder were specifically developed to provide a framework for systematic and comparative data collection by case study and this they broadly achieved ${ }^{18}$.

The six governance criteria used in Stern and Holder and the study for the ADB were:

1) Clarity of Roles and Objectives

2) Autonomy

3) Participation

4) Accountability

5) Transparency

6) Predictability

$17 \quad$ See inter alia Stern (1999)

18 The Stern-Holder criteria were also used as a major starting point for the electronic/postal questionnaire developed by Preetum Domah that provided the data for the empirical work in Domah, Pollitt and Stern (2002). 
In the terminology of Stern (1997), numbers 1, 2 and 4 were identified as indications of formal (e.g. legal) accountability and 3, 5, and 6 as measures of informal accountability (e.g. the practical operation of regulatory practices and processes). Given the current interest in data collection, it is worth replicating here the full amplification of the six criteria and the questions on which information was gathered - and successfully gathered. This is done in Table 1 below.

The most obvious feature of the detailed questions is that each section starts from questions about formal, legal obligations but rapidly moves into areas of regulatory behavior and what actually happens in practice. This pattern was very much replicated in the main report and the 13 sector reports, each of which was 5-10 pages long $^{19}$. (Note that the reports were not complied by questionnaire interviews; the information was collected by a set of UK and local country based experts using the Table 1 question list to guide and organize the collection and structuring of the data.)

19 See "Governance and Regulatory Regimes for Private Sector Infrastructure Development" A report by NERA for the ADB, ADB RETA 5758-REG, Manila, 1998. The results are discussed in Section 2.2 below. 


\section{Table $1 \quad$ Stern \& Holder Regulatory Criteria}

\section{Clarity of Roles and Objectives}

- Does the primary legislation set out a clear definition of the regulator's functions and duties?

- If not, are these functions and duties formally set out in legal instruments and/or other documents?

- Is it clear where the regulator has an advisory role (eg to the Minister) rather than a decision making role?

- $\quad$ Are there any functions carried out jointly, or any that are ambiguous, between the regulator and those of the relevant Minister(s)?

- Does the legislation establish unambiguously which entity is responsible for what regulatory functions?

- Does the regulator have any responsibility for commercial activities?

2. Autonomy

- What is the relationship between the regulatory body and the government (eg a separate division of a Ministry, a body independent of any Ministries, a body independent of government, etc)?

- How are members of the regulatory body appointed and dismissed?

- How is the regulatory body financed? Who has to approve the funding?

- In what cases does the regulator have only an advisory role (rather than a decision making role)?

\section{Participation}

- Does the regulator formally involve regulated firms, other industry firms, consumers and others on:

- major decisions?

- $\quad$ the proposed approach to taking major decisions?

- Are consultation responses made public (either in full or in a summary of responses)?

- Does the regulator comment publicly on points made in consultation responses, and how (if at all) these have affected the final decision?

- Are there any other indications of whether or not consultation responses influence the final decision?

- What other ways are industry participants (including firms and consumers) involved in regulatory decision making and processes? 


\section{Accountability}

- Is there a formal mechanism for regulated firms (or other parties) to challenge regulatory decisions?

- If so, how does it work? And has it been used?

- Is there also a legal right of redress?

- Do firms or other parties comment (or even challenge) decisions through informal channels (such as direct representations to Ministers, or through the media)?

- To whom is the regulatory body accountable (government, parliament, courts)?

- Does the regulator have to answer questions before parliament?

- $\quad$ Can the regulator be dismissed for failing to fulfil his duties?

- $\quad$ Is there under primary law a facility for judicial review?

\section{Transparency}

- Are major regulatory documents (eg licences) in the public domain?

- $\quad$ Does the regulator publish major decisions (or advice)?

- Does the regulator publish the reasoning behind major decisions?

- If decisions/reasons are published, is this voluntary or compulsory (eg a legal requirement to justify decisions)?

- If decisions/reasons are not published, are any participants (such as the firms themselves) told of the reasons for major decisions?

\section{Predictability}

- How easily can the regulator's functions and duties be changed and what is involved?

- How easily can key regulatory documents (eg licences, authorisations, franchise contracts, etc) be changed and what is involved?

- To what extent are regulatory principles (eg, on the procedural approach to tariff reviews, the definition of the rate base or the rate of return which a firm should be allowed to earn) set out formally?

- Have the regulator's decisions demonstrated a consistent approach?

- Is there a published timetable of regulatory events every year?

- To what extent are regulatory arrangements in the sector part of a coherent approach (ie echoed in other infrastructure sectors) and to what extent are they ad hoc (ie different in institutional structure from other infrastructure sectors in the country)? 
In terms of key governance characteristics, little has changed in recent years. This is reflected in the recent survey by Kessides (2004). He uses a set of criteria for an effective regulatory system taken from Noll (2001). These are;

1) Coherence

2) Independence

3) Accountability

4) Transparency

5) Predictability

6) Capacity

We pick up issues of regulatory capacity in Section 3 below. However, the other five are clearly virtually identical to the criteria identified in Smith (1997) and Stern and Holder (1999).

The main developments of the discussion and appraisal of regulatory governance in recent years have been an increased emphasis on the experience in practice of DTE regulatory arrangements. This is reflected in Noll's 2001 reference to regulatory capacity and to the discussion of this and other problems of the practical experience with utility regulatory arrangements in DTEs discussed in Kessides (2004) and which we discuss in Sections 3 and 4 below. 


\section{Survey Evidence on DTE Regulatory Governance in Practice}

A considerable amount of information has been collected on the degree to which DTE utility regulatory institutions conform to good practice.

The clear picture that emerges from this is that practice has been disappointing, particularly in areas such as transparency and predictability. Moreover, DTE governments have rarely been able to resist the temptation of interfering with regulatory processes and decisions they dislike - Botswana is an exception and there are others but they are unfortunately infrequent. In addition, there is sometimes evidence of collusion between governments and regulated incumbents to outflank or outwit regulatory agencies ${ }^{20}$.

Most of the evidence collected has been in the form of non-comparable - if highly informative - case studies. Much of the force of the 1994 Levy and Spiller paper came from its case studies and there have been many more since. The case studies and the general conclusions that can be drawn from them have been surveyed in Kessides (2004). The problem with such evidence is that it cannot be used for systematic econometric or comparative empirical analysis.

There are, however, now several studies of regulatory governance covering a number of sectors/regions/countries and based on a systematic survey approach that provides consistent data. In this section, we summarise the results of three studies:

(i) The 1998 NERA report on six Asian developing countries as reported in Stern and Holder (1999);

(ii) The Prayas Energy Group's 2003 report on Indian State Electricity Commissions;

(iii) The 2003 EBRD report by David Kennedy on energy regulators in CEE and CIS countries and similar studies.

Unfortunately, there does not seem to be a survey paper covering Latin America, although there are many case studies which suggest serious problems in making utility regulation effective ${ }^{21}$. For Africa, Brian Levy's 2002 World Bank paper provides some useful related information.

\subsection{The 1998 NERA Report on Six Asian Developing Countries}

In Section, 2.1 above, we drew attention to the early but increasing attention given to regulatory practice and "informal accountability" relative to formal, legal accountability. The key summary table of the 1998 NERA report allows us to demonstrate this clearly as the criteria can reasonably be divided into three formal

20 See, for example, Estache's 2002 discussion of Argentinian utilities privatization and Stern (2000) on CEE countries.

$21 \quad$ See Noll (2000). Kessides (2003) has many examples. 
governance attributes and three informal (practice/process) attributes. This is shown in the reformulated version of the key summary table of the report shown below ${ }^{22}$.

The key point to note in Table 2 is that, with the exception of Indian gas and telecoms, all the scores on the informal attributes of regulatory governance are lower than the scores for the formal, legal attributes. The scores for transparency are particularly low.

It is also worth recognizing:

(i) In retrospect, the NERA 1998 survey over-estimated achievements in developing effective regulatory frameworks in practice in the Asian countries considered $^{23}$.

The scores on the three informal accountability attributes would have been significantly reduced for the highest marked sectors if the study had been carried out 1-2 years later. This applies to Orissa electricity, Indian telecoms and (particularly) Pakistan electricity, the main apparent successes as seen in 1997-8. In retrospect, for all three cases, and particularly Pakistan electricity, too much weight was given in the survey to stated plans for the establishment and enhancement of regulation rather than to actual achievements. This shows the inherent risks of optimism bias in even the best surveys.

(ii) In retrospect, the degree to which the NERA survey captured aspects of regulatory practice was relatively limited.

The regulatory bodies, particularly the new, independent ones were, in 1998, simply too recently established to be have enough of a track-record of experience on which they could be appraised. In consequence, both the topic list in Table 1 above and the results are heavily weighted to aspects of the law and to legal obligations relative to actual regulatory practice. This is true even for aspects of regulatory practice such as Transparency and Predictability. This was unavoidable at the time but means that current and future studies should enhance the "what regulatory agencies actually do" aspect relative to the "what regulatory agencies are required by the law to do".

\footnotetext{
22 For clarity, the scores in Table 2 above have been converted from the published A- E to 1-5, as was originally intended.

23 The same is true of the results in the Stern-Holder paper which were drawn directly from the 1997 NERA survey.
} 
Table 2: Rankings of Asian Utility Regulation Frameworks, 1998

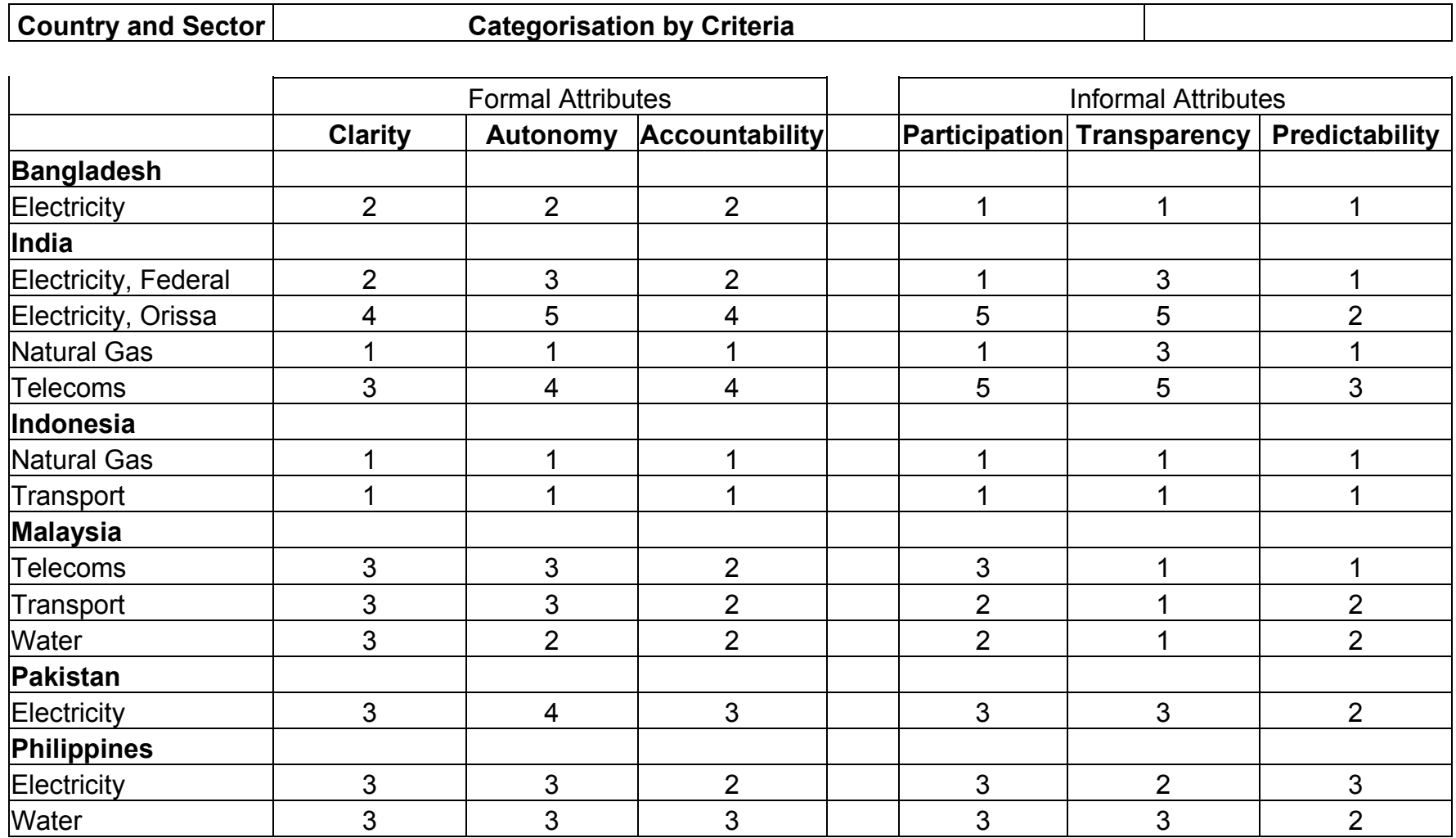

Scoring: Each sector was ranked on a 1-5 scale where 1 indicates no merit with regard to the criteria for effective and independent utility regulation and 5 represents best OECD practice.

Source: "Governance and Regulatory Regimes for Private Sector Infrastructure Development" A report by NERA for the ADB, ADB RETA 5758-REG, Manila, 1998, Table 3.8 also Stern and Holder (1999) Table 2.

\subsection{The Prayas Energy Group's 2003 Report on Indian State Electricity Commissions}

The Prayas Report ${ }^{24}$ (2003) is a fascinating document. Since the study was carried out when there had been a reasonably long period under which Indian State Electricity Regulatory Agencies had been in place, it was able to go much further than the 1998 NERA study in providing substantive and systematic analysis of the performance of regulatory agencies in practice.

$24 \quad$ "A Good Beginning But Challenges Galore: A Survey Based Study of Resources, Transparency and Public Participation in Electricity Regulatory Commissions in India", Prayas Energy Group, Pune, February 2003. 
Again, the dominant feature is the ways in which the formal, legal attributes of regulatory governance of India's electricity industry are being undermined by poor practice on the informal attributes on transparency, participation, etc. The report also documents the lack of support and, in some cases, active hostility from the power companies and State Governments. In some states, the "rules of the game" on utility regulation are clearly not agreed between the parties let alone being observed. The evidence of the report shows clearly that both the power companies and the State Governments are, in many cases, trying actively to subvert the processes, requirements and conventions that underpin effective and independent regulation including requirements of the law and legal process.

The Prayas Group sent a questionnaire (unfortunately not reproduced in the report) to 12 Indian State-level Electricity Regulatory Commissions (ERCs) and the Central Electricity Regulatory Commission in May 2002. All replied apart from Haryana ERC. The questionnaire covered issues such as:

$\begin{array}{ll}\circ & \text { Commission Staff and Resources } \\ \circ & \text { Use of Consultants } \\ \circ & \text { Review and Implementation of Commission Orders } \\ \circ & \text { Transparency; and } \\ \circ & \text { Participation. }\end{array}$

The information collected was supplemented by use of ERC Annual Reports (where published), minutes of meetings and ERC websites.

The report demonstrates very clearly the difficulties involved in creating viable and effective regulatory agencies in India and countries like it. A critical issue identified in the conclusions is whether it is possible to have effective regulatory agencies in countries unless there are "strong and vigilant civil society groups" and effective consumer representation ${ }^{25}$. One of the reasons for this question being posed is the finding by the Prayas Group that the State Governments and incumbent power companies initially seemed to under-estimate the potential power of the ERCs and are now working actively (sometimes collusively) to remove the threat of ERC effectiveness.

(Note that the Prayas Group did not discuss the structure of Indian electricity utilities. The regulatory governance problems reported may have been made significantly worse by the continuing prevalence of state ownership together with the near total absence of any competition in generation or supply.)

Among the key findings of the Prayas Report are:

- Inadequate funding levels

$25 \quad$ Prayas Report op cit, p 45. 
○ 7 out of 12 reporting ERCs had less than $70 \%$ of their proposed budget in one of the last 2 funding years

- Grossly inadequate staff resources:

- On average, ERCs had approval for 8-10 professional and technical staff. Only Andhra Pradesh approval for more than 20 while West Bengal and Maharashtra had approval for only 2 professional and technical posts. Requests for additional professional and technical staff for are delayed for months or years.

- The average number of authorized administrative posts is around 20-30 but many of these posts were left unfilled for various reasons (State Government unwillingness to allow them to be filled, low pay, etc.)

- 8 out of 12 reporting ERCs had no permanent professional and technical staff. Andhra Pradesh had 8 permanent professional and technical staff and Orissa had 12; none of the others had more than 3

- Many of the professional and technical staff are on loan from the incumbent utility.

- Problems over Appointment, Continuity and Independence of Regulatory Commissioners

- The laws establishing ERCs specify 5-year terms for Commissioners but require Commissioners to retire at 62 . Many of the Commissioners appointed are aged around 60 at the time of appointment so cannot serve more than 2-3 years before they are obliged to retire.

- Most of the Commissioners are ex-Indian Civil Service with a substantial proportion from the power companies.

- Serious problems in implementing and enforcing compliance with ERC directives

- Utilities strongly resisted providing the necessary data to the ERCs and on occasion presented misleading data.

O Utilities particularly resisted attempts by ERCs to obtain data on investment plans -4 of the ERCs reported that the utility refused to allow any regulatory scrutiny of investments.

- Utilities proceed with actions eg on tariff changes without permission from the ERC or even when the ERC has refused the utility's application. 
- Failures by the ERCs to meet their procedural obligations

○ 5 out of the 12 ERCs had never published an annual report

- Only 1 ERC (Karnataka) has conducted the minimum mandatory number of Commission Advisory Committee meetings and only 4 prepare action note or other responses.

- Transparency and public participation are very weak

- There are virtually no lists of available documents or reading rooms. Many supposedly publicly available documents are unavailable.

- Only some orders and other information are available on websites.

- ERCs are issuing discussion papers and methodology papers but only in a form usable by experts.

\section{- $\quad$ There are major and growing numbers of disputes with State Governments}

- State Governments have intervened in ERC decisions by use of policy directives - in some cases (particularly Delhi and Karnataka) by directives whose content was against the primary law.

○ State governments are consistently failing to pay the promised subsidies needed to validate ERC tariff rulings.

On this last crucial issue, the Prayas Report concludes:

"The analysis in this section depicts many disturbing trends that would make any concerned citizen sit up. These include highly deplorable activities in which some state utilities and state governments indulge in order to avoiud public scrutiny of their governance. In doing so, they are flouting with impunity not only all norms, but even legal obligations, demonstrating complete disregard and disrespect for many things that governments are expected to hold dear.... Private utilities have resorted to equally deplorable tactics.” (Prayas Report op cit, p.40)

This is a pretty damning verdict, even taking account of the fact that it is in a report by an NGO whose business is the encouragement of civil society obligations and transparency. No wonder that the Indian experience with State level electricity regulators has pushed observers to promote regulatory solutions that, at least for the first few years constrain or eliminate regulatory discretion within a contractual 
framework $^{26}$. However, that is only a solution for the first few years and the problem remains not only how to build in the necessary flexibility but also how to exit the constraints after the initial period.

Although the Prayas Report demonstrates clearly that there is a very long way to go before ERCs meet the standards of good regulatory governance, they do not argue that the effort has been a waste of resources. Indeed, they are (cautiously) optimistic about the potential development of the ERCs as effective regulatory agencies.

Given the starting circumstances, it is quite possible that the developments to date are a significant improvement on the previous implicit regulation by State Government agencies. (The Prayas Report dos not assess this.) They certainly seem to have provided some openness, division of powers, pressure for commercialization and open debate. Indian ERC development to date may be all that could reasonably have been expected. However, the key question unfortunately remains completely open. Is the glass half-empty or half-full? What are reasonable expectations in this area - for SubSaharan Africa, Russia and other CIS countries as well as for India and other Asian economies?

The fact that the Prayas Report provides the evidence with which to conduct such a discussion again shows the potential for using structured case studies to examine these issues. To assess the impact of regulatory arrangements on outcomes of course requires marrying data on investment, consumption, etc with regulatory data - but the Prayas Report confirms that this regulatory data must go a lot further than scrutiny of legal and related documents.

It is only unfortunate that the Prayas report did not code its findings (a) on regulatory actions and (b) on the formal requirements along the lines of the 1998 NERA report (and Stern-Holder). A sound and robust coding framework is the essential next step in further work of this kind.

\subsection{The EBRD Study of Power Sector Regulatory Reform in Transition Economies and Similar Studies}

\subsubsection{The EBRD 2003 Study}

This 2003 study by David Kennedy reports results from a survey carried out by EBRD in conjunction with the World Bank. Tables 2-4 of the Kennedy study report performance with respect to 6 governance criteria $^{27}$. The criteria are:

Separate (non-Ministry) regulator

Fixed term appointment for regulator

$>$ Funding by industry (eg by licence fee)

$>$ Full tariff setting powers (ie tariff decisions made by regulator)

\footnotetext{
26 See, for instance, Bakovic, Tenenbaum and Woolf (2002) who argue this case for electricity distribution.

$27 \quad$ See Kennedy (2003), pp 10-11
} 
Transparency (ie regulator has statutory obligation to explain basis for decisions)

$>$ Redress (ie appeal rights)

This list includes a key aspect of regulatory practice - transparency. However, the study only looks at whether and how this is covered in the law. Indeed, it seems that the study is only a study of Electricity/Energy $\operatorname{Laws}^{28}$. In consequence, there is no indication of whether, how and how far the letter of the law is reflected in regulatory practice nor how the spirit of the law is interpreted.

The Prayas Report and, to a lesser extent, Stern and Holder (1999) show how regulatory practice can and is typically significantly different from what legal provisions would lead one to expect. This is confirmed in numerous one-off case studies as discussed in Kessides (2004). Similarly, Stern (2000) and (2002) - as well as the EBRD 2001 Transition Report on Energy - would suggest that the actual performance of regulatory frameworks for electricity in transition economies is significantly different from the relatively optimistic picture set out in the Kennedy tables.

In fairness, Kennedy's paper supplements the tables with brief descriptions of the electricity regulatory experience in Hungary, Kazakhstan and Moldova. These descriptions do bring out clearly the gap between de jure provisions and de facto experience. Nevertheless, counting the positive entries as a proportion of the total, Kennedy's Table 2 provides a picture for Central Europe and the Baltic States of a glass that is over $80 \%$ full. This is not what one finds in the case studies, nor what one finds in the papers referred to above.

The importance of this example is not to criticize the Kennedy paper. Rather it clearly demonstrates that data based on analysis of laws without collection of information on practice are, at best, seriously problematic; and, at worst, may be biased and misleading.

\subsubsection{The 2002 Indian Ministry of Power Study}

There are other studies (including the econometric studies of regulatory effectiveness that we will discuss below) which rely largely or wholly on studies of laws and formal regulatory governance properties but which provide little or no detailed examination of regulatory practice. We will not discuss these here as they add little additional information. There is, however, a study for Indian electricity regulation, which contrasts interestingly with the Prayas study and which shows the limitations of primarily paper-based studies (as well as the issue of the relative assessment/marking standard).

The Ministry of Power in India commissioned (apparently in 2002) an appraisal of power sector reform and a performance rating for 26 Indian states by CRISIL/ICRA. The study was primarily from paper records, but supplemented by face-to-face meetings with SERC members, heads of utilities, etc.

28 Unfortunately, the paper does not explicitly record the data collection methods for the $\mathrm{EBRD} / \mathrm{WB}$ study of regulators. 
The relative rankings between States are broadly similar to those in the Prayas Report, although some jurisdictions to which the Ministry of Power gave good marks for regulation were heavily criticized in the Prayas Report - notably Haryana and Delhi State. However, the absolute scores in the Ministry of Power's report suggest a much more optimistic picture than in the Prayas Report. For most of the major reformers in the Ministry of Power report, SERC factors were given marks of 15 or more out of 20 (ie the glass was three-quarters full or more). The states so categorized were: Andhra Pradesh, Karnataka, Haryana, Rajasthan, Delhi State and Uttar Pradesh. This list and the judgments on the adequacy of the SRC's in some of these States - is not only very different from that in the Prayas Report but also from that of other observers.

\subsection{Conclusions from Surveys of Regulatory Governance Practice}

The key conclusions from this section are:

1) It is possible to operationalize the measurement of informal as well as formal regulatory governance by systematic, structured case studies using a common framework.

Note that this typically requires probing under a framework of headings by informed observers. It cannot, in practice, be carried out by fully specified questionnaire-driven interviews and particularly not by web-based/e-mailed or postal questionnaire. The latter are only suitable for collecting basic information on formal governance characteristics, as in the EBRD/WB survey of transition country regulators and the Domah survey used in Domah, Pollitt and Stern.

Establishing a strong, common coding framework is crucial for the success of such studies.

2) For DTEs, studies that concentrate on formal governance characteristics alone typically over-state the quality of regulatory governance, usually by substantial amounts.

In addition, studies of regulatory practice can only reliably be made after the regulatory agency has been in place for a reasonable period (eg 2-3 years or more).

3) As a consequence of 2), econometric studies that use indicators of regulatory governance based only on formal characteristics may provide poor and biased estimates of regulatory effectiveness.

We will discuss this last point in more detail in Section 5 below. 


\section{Resources Available to Utility Regulatory Agencies in DTEs}

This is an issue of which there has been general awareness for some years. Attention has been focused on two different aspects:

(i) Financial resources; and

(ii) Human capital resources - particularly the availability of scarce, highly skilled professional staff resources.

The former is a relatively straightforward issue where the willingness to provide and ensure adequate funding is essentially a sign of the commitment (or the lack of it) by governments and/or legislatures to accept independent regulation in practice. It is very rarely if ever a genuine question of resource insufficiency. The human capital resource issue is the more serious problem and the one on which we will focus in this paper.

Warrick Smith's 1997 World Bank Public Policy for the Private Sector Notes included some discussion of the issue as, in passing, did Levy and Spiller (1994) in their discussion of the role of resource endowments. In particular, Smith's papers considered the case for having multi-industry or multi-sector regulators as a way of economizing on scarce, specialist staff resources. Noll (2000) also raised the issue in the context of whether countries should combine to provide multi-national regulators.

These papers all discussed the issue from the perspective that an inadequate supply of staff with good regulatory knowledge and experience would lead to poor and longdrawn out decision-making. Inadequate regulatory resources would particularly jeopardize discretionary regulation. Hence, this became an important issue for those who advocated regulation by contract rather than by agency.

Data on the number of regulatory staff in a large sample of DTE agencies was first systematically reported in Stern (2000). Drawing on World Bank and other sources, he reported staff numbers in electricity or energy regulatory agencies for 24 countries. For African countries, staff numbers were clearly low (around 20) and in some cases under 10. However, Argentina, Brazil, Mexico, Malaysia and the Philippines all had over 140 staff, although there was still the question of whether they had adequate numbers of experienced regulatory professional staff (eg accountants, economists and lawyers $)^{29}$.

The discussion of the whole topic was advanced considerably by Domah, Pollitt and Stern (2002) - henceforth DPS (2002). Using a purposed-designed postal and e-mail survey, information was collected for electricity regulators ${ }^{30}$ in 60 countries on (a) numbers of staff and (b) numbers of professional staff. Data was also collected on a

\footnotetext{
29 Stern (2000) also reported staff numbers for 13 mainly developed country telecom regulators reported in Buckle (1999). The staff numbers for telecom regulators did not indicate as serious a problem on staff numbers even for relatively low income countries like Jordan or Peru. Including energy and multi-sectoral regulators.
} 
number of other regulatory and system attributes to enable the estimation of equations to predict the numbers of staff required.

The data were of generally high quality although there were some question marks for individual country responses. More importantly, the definition of "professional" in numbers of professional staff may well have been rather different (and less demanding) for many DTEs relative to the North American and EU countries in the sample.

The DPS data confirmed that there were fixed staff costs for countries establishing an electricity regulator. This raises serious problems for small countries like Grenada or Namibia. They also, however, showed that developing country regulators had noticeably higher staff numbers per million customers per sector regulated - a mean number of 59 staff per million for developing countries as opposed to a mean of 15 per million for developed countries. The difference was that developing countries had a much lower number of connected customers relative to population. Plotting average cost curves, developing countries were concentrated in the relatively steep initial portion of the curve, with many above the fitted line ${ }^{31}$.

The data above indicate some of the difficulties for developing countries in establishing an effective regulatory capability. This was demonstrated more directly in the econometric equations used to explain staff numbers and professional staff numbers. The estimates from the regressions suggested that, even for small countries with limited electricity systems, the minimum number of regulatory staff required was around 30-35, including around 15-20 professional staff. Predictions using the relevant equations for three small, developing countries not in the DPS sample Guatemala, Sri Lanka and Zambia - yielded the following numbers for staff requirements:

\section{Total Staff Professional Staff}

$\begin{array}{lll}\text { Guatemala } & 58 & 33\end{array}$

Sri Lanka $\quad 48 \quad 26$

$\begin{array}{lll}\text { Zambia } & 57 & 45\end{array}$

Clearly, many developing countries do have staff (and professional staff) numbers at or above the DPS predictions. Latin American regulators generally seemed to be well-staffed and to have more staff (and professional staff) than the DPS equations predicted. That was the case for several of the regulators in smaller and poorer Latin American countries (eg Bolivia, Ecuador and Peru). However, many DTEs particularly smaller African and Caribbean countries - have significantly fewer staff than predicted (eg Kenya, Grenada). But, even here, the results were not always toward significant under-prediction viz. Uganda, a major African electricity reformer,

$31 \quad$ See DPS (2002), pp 19-25. 
where the actual numbers of total and professional staff in 2000 were 12 and 5 respectively but where the predicted numbers were 7-19 and 3-5 (with the range bounds depending on whether the equation used for prediction was the whole 60 country sample or the 26 developing country sub-sample.) ${ }^{32}$

The problem of inadequate staff and professional staff numbers that emerges from the estimates in DPS (2000) does not seem to be as acute as previous work may have suggested but is still far from trivial - at least in Africa and the Caribbean. Whether or not it affects regulatory outcomes (eg investment and output growth) is a separate issue to which we will return in our companion paper.

However, case studies have shown that many DTE regulatory agencies, even some of the most lavishly staffed, have difficulties in handling key issues in regulatory economic practice (eg establishing a proper regulatory asset base, setting interconnection/access prices, etc). The apparent resource deficits reported from the DPS results are less relevant if there is a resource deficit and it is primarily on the quality of the key regulatory staff rather than a quantity issue relating to the numbers of total or professional staff. Unfortunately, as yet, no data seems to have been collected systematically on the quality of regulatory staff in different countries. It is another regulatory practice topic. In addition, it is a difficult topic on which to collect data, particularly across the range of DTEs. It might perhaps be collected within a systematically structured cross-country case study approach.

$32 \quad$ See DPS (2002), pp 33-42. 


\section{Studies of the Effectiveness of Independent Regulatory Agencies and Governance Arrangements on Utility Industry Outcomes}

\subsection{General Issues}

The literature on estimating the effect of regulatory governance arrangements on outcomes is relatively small to date, particularly for electricity. There has been more for telecoms, particularly in recent years and we will draw on this in what follows. We will also refer to the recent work on infrastructure concession contracts in Latin America that has been done in and around the World Bank where the probability of renegotiation appears to be affected by the presence or absence of a regulatory agency - but how and why is unclear.

The larger literature for telecoms arises because there has been more and earlier DTE privatization and regulation for it than for other infrastructure industries. Not only does this mean that there is a longer observation period - and hence more chance of finding significant effects - but also that comprehensive databases have been assembled. The main one seems to be the ITU-World Bank database on telecommunications policy and regulation, but this can be supplemented by the Stanford-World Bank database (which covers mobile telephony in Latin America) and others.

For electricity, DPS (2002) report a figure of 4 years as the median duration of developing country electricity regulators (as of late 2000). Given the time needed to establish the effective working of regulatory institutions - let alone the time needed to establish their reputation and credibility - it is hardly surprising that, as yet, it has been difficult to make any robust estimates of the impact of regulation on outcomes.

In this context, it is worth noting that regulators established in the late 1990s were trying to develop their role around or after the time of the Asian and other financial crises and the much more difficult circumstances as the 1990s boom disintegrated. This also makes it harder to establish positive effects (eg on investment) than for telecoms.

For electricity, there is also, as yet, no database comparable to the World Bank/ITU database for telecoms. The data position is substantially weaker for railways and other transport infrastructure industries, water and sewage and, to some extent, for natural gas, primarily because there has been much less DTE privatization, unbundling or establishment of independent regulatory agencies. To our knowledge, virtually all of the relevant systematically collected data for these industries in DTE countries derives from Latin America via the Guasch et al World Bank data set on concession contracts and the Calderon-Serven data set (which ends in 1998) ${ }^{33}$.

A fundamental point to note is that none of these data sets includes data on the informal attributes of regulation (ie observations on transparency and other elements of regulatory practice). This is in contrast to many of the estimates which have been made of the effect of independent central banks on macro-economic outcomes. The implication is that all the econometric results based on these data sets for telecoms, electricity and other utility industries may provide downward-biased

33 See Caderon, Easterly and Serven (2002) for a full description of this data set. 
and/or inefficient estimates of the true effect of regulation and key governance characteristics.

We will discuss this bias and provide some indications of its potential magnitude in Section 5.1.3 below.

All the studies of the impact of independent regulation (and specific governance characteristics on outcomes share some common features:

(i) The difficulty of defining appropriate measures of outcome and

(ii) Methodological problems in empirical work.

(iii) The errors-in-variables problem in measuring the effectiveness of regulatory agencies and governance factors.

We discuss each in turn below.

\subsubsection{The Difficulty of Defining Appropriate Measures of Outcome for Utility Regulation}

The objectives of regulation in developed countries such as the US and Canada, the UK and other EU countries are broadly as follows:

1. Increase efficiency and quality of service

2. Reduce costs - both operating costs and the costs of investment

3. Reduce prices to final consumers so that prices correspond to the economic costs of supply

4. Allow companies and investors to have the expectation of a normal rate of return (for regulated, monopoly elements)

5. Enforce competition policy goals and prevent market abuse in potentially competitive elements

6. Reduce excess capacity margins

7. Maintain universal service obligation

In particular, North American, EU and similar regulators are typically judged on

(a) how far they have been able to reduce prices to final consumers;

(b) how far they have maintained or improved the quality of performance; and

(c) how far they have been able to reduce investment needs consistent on maintaining (a) and (b) ${ }^{34}$.

34 This would apply primarily to electricity, water and possibly the transport industries - not to telecoms. 
The position is very different in DTEs.. For all DTEs, objectives 1 and 2 are common as is (b). But their other objectives are typically different.

Firstly, most infrastructure industries need additional investment (including maintenance and rehabilitation) both to maintain and improve the quality of service to existing consumers and to extend service to currently unserved people and areas ${ }^{35}$. Hence, a major test for developing country regulators is whether they can increase investment levels not whether they can be reduced. (Similarly, in developed countries, effective regulation is likely to be associated with slower growth in energy use or water leakage - at least relative to GDP growth; whereas in developing counties, it is likely to be associated with more rapid output and consumption growth.)

Secondly, although there are some developing countries where the prices charged to final consumers are above those corresponding to economic costs in an efficient system; in many more DTEs, the prices are substantially below full economic cost particularly for household and small agricultural users. In such cases, utilities do not cover their capital costs (including an adequate real rate of return) and existing, connected customers are over-protected on prices relative to unserved people and areas as well as to private investors/taxpayers.

For water and sewage, maintaining excessively low retail prices to small customers is the norm across all DTEs, including Latin America. For electricity, some Latin American countries had (or have) average prices and prices to small customers above long-run economic cost (eg pre-reform Argentina and Chile, Uruguay). However, in other Latin American countries (eg Ecuador, Venezuela) as well as in most of Asia, much of Africa and all CEE and (particularly) CIS countries, prices are typically far below long-run economic cost. Hence, for countries in this category, raising prices is the positive outcome for effective regulation ${ }^{36}$.

Of course, raising prices (where necessary) is an intermediate rather than a final regulatory output. The truly final outputs are growth in efficiency, quality and the supply of output. For countries like India, Russia and those mentioned above, the crucial policy issue is to increase supply by raising the efficiency and availability of plant, the quality of service and - particularly - investment. But, if investment is to be primarily privately financed, that implies higher prices. Regulatory action to increase prices is part of the commercialization and modernization package - and the most controversial one.

In consequence, the relevant direction of change for several regulatory outcomes - at least in electricity and water - is the opposite in some or all developing countries from what it is in North America, the EU and similar countries. This is in distinct contrast with tests of the effectiveness of independent central banks (ICBs) where the relevant

\footnotetext{
35 This would not apply to electricity in the European transition economies where service is universal and there is a history of over-investment resulting in an excessive, if poor quality, capital stock.

36 For telecoms, reducing absolute prices is not the issue given the rapid rate of cost-reducing technological progress and high economics of density. For telecoms, the equivalent issue is price rebalancing eg between line rentals and call charge and between local, long-distance and international call charges. This is not a huge problem - much less acute than for water or electricity - given the buoyant demand for the most sophisticated and expensive telecom services by businesses and households.
} 
output criteria - low inflation and higher average GDP growth - are the same for all countries. The issue also creates significant practical problems in estimating the effectiveness or regulators on outcomes since it may cause problems in combining developed and developing country samples. (CEE and some CIS countries are, at least for electricity, in an intermediate position.)

\subsubsection{Methodological Issues in Empirical Work}

These issues are serious but less fundamental than the problem of defining relevant output measures discussed above.

Empirical testing of the performance of regulation seems now to concentrate on the application of panel-data econometrics. (See Fink, Mattoo and Rathindran (2002). Guasch, Laffont and Straub (2002) Gutierrez (2003) and Pargal (2003) for good recent examples.)

Case studies provide interesting narrative pointers but cannot allow a statistically robust separation of the effects of other changes (e.g. commercialization, privatization, unbundling, the introduction of competition, etc) from the impact of the establishment and development of an independent regulatory agency. Cross-section econometric modelling faces huge problems of multi-collinearity between the relevant independent variables and simple time-series modelling per country is not relevant to the underlying question.

Panel-data modelling creates various problems regarding the quantity or quality of data (e.g. with missing observations, an unbalanced panel, etc.) Panel data also allow the possibility of taking explicit account of country-specific effects - fixed or random. These issues and others raise important questions for any estimation strategy on the appropriate specification of the error term. In consequence, the eventually obtained coefficient estimates, standard errors and test statistics depend on a number of critical econometric assumptions, the choice of which is not always obvious ${ }^{37}$.

Another major issue is the fact that countries are more likely to adopt and encourage effective regulatory agencies the more that they have a positive attitude to the separation of powers, the commercialization of economic activities and to private investment and market economics in general. Hence, one should not assume that independent regulators are exogenous. In all areas of the world, countries will select whether they want to go down the route of commercialisation and independent regulation. Early adopters in particular are likely to be heavily self-selecting.

This endogeneity problem is well-known in the ICB effectiveness literature ${ }^{38}$. It has surfaced in the regulatory effectiveness literature. Two recent examples are in Gual and Trillas (2002) and Guasch, Laffont and Straub op $\mathrm{cit}^{39}$.

Gual and Trillas discuss the impact of 37 telecom regulators and they instrument the degree of independence of the regulator which is measured by an index, following the ICB effectiveness literature. The degree of regulatory independence is estimated

37 See Fink, Matthoo \& Rathindran op cit, Appendix 4, pp 32-3 for a good discussion of some of these issues in the context of telecom regulation.

38 See, for instance, the survey of ICB empirical studies in Berger, de Haan and Eijffinger (2000). We will discuss this and related issues in Section 2.5 below.

39 See also Gutierrez (2003) which has a detailed investigation of endogeneity issues in telecom regulation. He finds little or no change in his estimates from allowing for endogeneity. 
(somewhat surprisingly) to be a negatively related to the existence (a) of an index of institutional restraint on the executive and (b) to a right-wing government and positively to the number of staff in the pre-reform telecom incumbent. In most cases, as one would expect, taking account of endogeneity reduces the t-statistics on the regulatory variable. However, the instrumental variable (IV) estimate for the impact of regulatory independence on network penetration is increased relative to the OLS estimate (but only at a $10 \%$ significance level) ${ }^{40}$.

Guasch, Laffont and Straub do not treat the existence of an independent regulator as endogenous; rather, they use the existence of the regulator as an instrument for the concession contract features that they believe are endogenous. As they recognize, this causes problems in the IV estimates of the impact of the regulator when the latter is included as a separate independent variable in addition to its use as an instrument. This points to the problem (emphasized both by Guasch et al and Fink et al) of the acute difficulty in finding appropriate instruments for the estimation of utility and regulatory reform outcomes.

\subsubsection{The Errors-in-Variables Problem where the Informal Governance Characteristics are Unobservable}

We have earlier identified that there is a potential errors-in variables problem from having data only on the formal characteristics of regulation (the legal framework) rather than data for countries both on the legal characteristics and on the actual development of regulatory practice.

In order to gain an idea of the potential quantitative effect of using only formal measures of the quality of the regulatory institutions in practice, we explored data from Stern and Holder (Table 2 in Section 2.2.1 above) on a range of 12 regulatory institutions in six developing Asian countries in 1998. This study divided the six effects into two groups:

(a) a group of 3 formal measures setting out features of the legal framework (Clarity of Roles and Objectives, Autonomy, and Accountability) ; and

(b) a group of 3 informal measures (Participation, Transparency and Predictability).

In fact, as we discussed earlier, the actual measures in (b) had a relatively high weight of legal aspects and planned developments relative to actual experience e.g. in price and other regulatory views, not least because so many of the regulatory agencies considered had been established only 1-2 years before the date of the survey. Hence, the "informal" aspects contain much less practice and rather more "formal" elements than one would like and this should be borne in mind when considering the simulation results reported below.

We took the true data generating process to be:

$$
\mathrm{Y}_{\mathrm{i}}=1.0 *(\mathrm{TF}+\mathrm{TI}) / 6+\mathrm{u}_{\mathrm{i}}
$$

$40 \quad$ See Gual and Trillas op cit, pp 9-18. 
Where $\mathrm{Y}=$ performance

$$
\begin{aligned}
& \mathrm{TF}=\text { the sum of the formal measures }(\text { mean }=7.38, \text { s.d. }=3.10) \\
& \mathrm{TI}=\text { the sum of the informal measures }(\text { mean }=6.38, \text { s.d. }=3.25) \\
& \mathrm{u}_{\mathrm{i}}=\text { a normally distributed error term }(\text { mean of zero, standard error } 2.5)
\end{aligned}
$$

In the Stern-Holder data set, as shown in Table 3 below, the measures of formal and informal regulatory quality are highly correlated with each other. In particular the correlation coefficient between the formal measures and the total index is 0.96 .

\section{Table 3: Correlation between Formal and Informal Measures of Regulatory Quality}

Correlation

\begin{tabular}{lrrrr}
\hline & \multicolumn{1}{c}{$T F$} & $T I$ & $O T$ \\
\hline TF & 1 & & & \\
TI & 0.852 & 1 & & \\
OT & 0.960 & 0.964 & 1 \\
\hline
\end{tabular}

Note: $\mathrm{OT}=\mathrm{TF}+\mathrm{TI}$

Source: Stern and Holder (1999)

\section{The Specification of the Problem}

Unless data have been specifically collected on the informal characteristics of regulatory quality, we are left only with the more easily obtained formal characteristics. To investigate the impact of this, we carried out illustrative simulations see the effect of using only formal measures of regulatory effectiveness when the true data generating process involves both the formal and informal measures.

The results are summarised in Table 4, which lists the results of the estimated coefficients for 12 simulation runs 
Table 4: Simulation Results

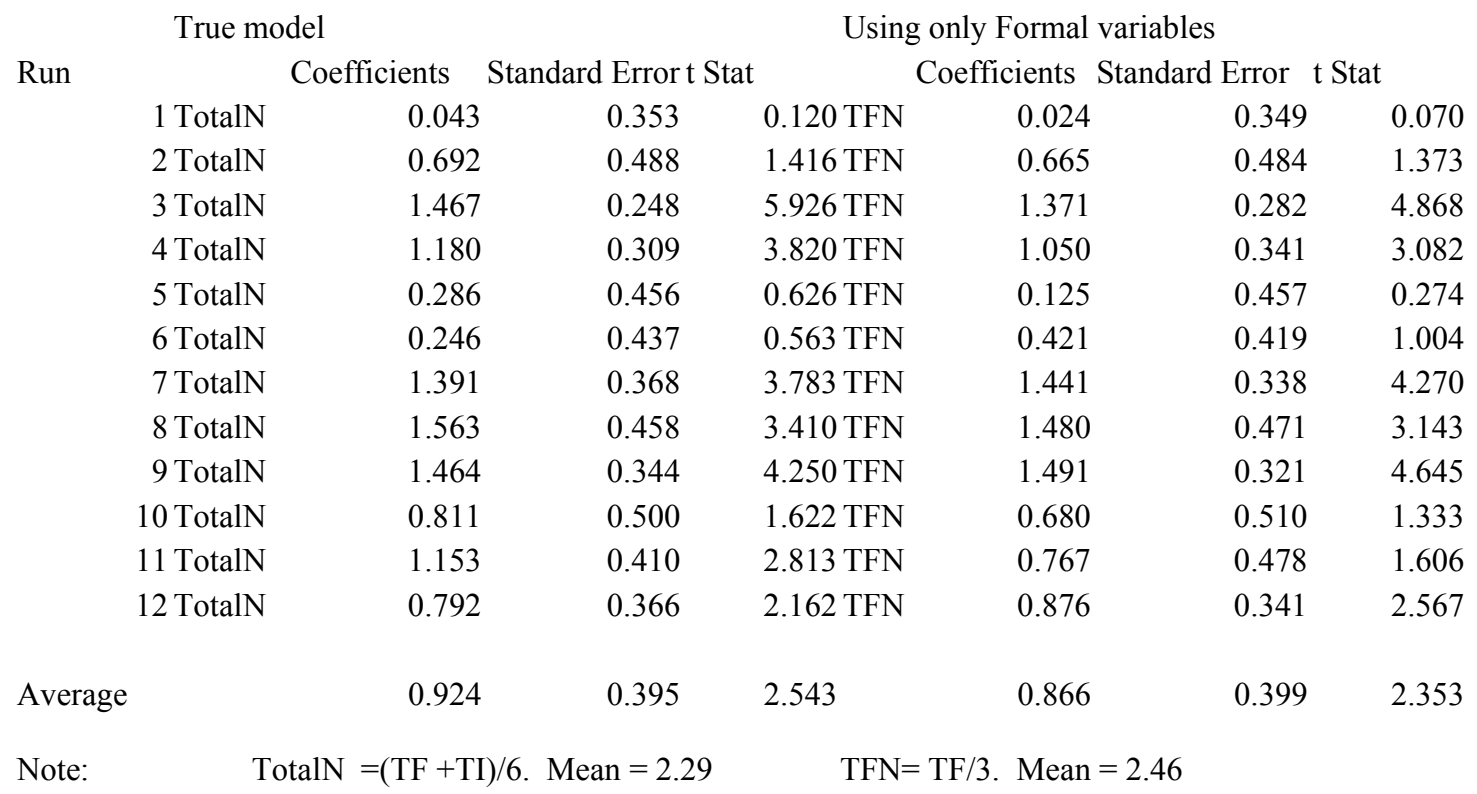

The key results from the illustrative simulations in Table 4 are:

(i) The coefficient (slope) estimates from using only the Formal measures of quality are about 5-10\% lower than from using Formal and Informal measures;

(ii) The estimated standard errors from using only the Formal measures of quality are about 1-3\% higher than from using Formal and Informal measures.

(iii) Estimated t-values are more often lower than higher from using only the Formal measures of quality but, on average, the difference was a reduction in estimated $\mathrm{t}$-values of around $7 \%$.

The illustrative simulation results from this data set would not justify abandoning the idea of carrying out empirical work with only the formal variables in place. This is encouraging in itself and supportive of the work that we report in our companion paper, which uses the DPS data on regulatory governance - which does not have information on regulatory practice.

We have, however, noted that the Stern-Holder data set contains relatively little data on regulatory practice, even in its informal measures - much less than the recent Prayas Report on Indian State Electricity Boards. Hence, it remains a priority to collect more and better information on regulatory practice and its development both in its own right and to test whether the results from the simulation analysis based on the Stern-Holder data set generalise to up-to-date and better data sets. 


\subsection{Empirical Studies of the Impact of Regulatory Agencies on Electricity Outcomes in DTEs}

To date, there have been very few studies applying econometric methods to a multicountry data set, including DTEs. We have found only two such studies that focus on this topic:

(i) Bergara, Henisz and Spiller (1998); and

(ii) Zhang, Kirkpatrick and Parker (2002).

There are some other studies which cover this topic among others. The most relevant is Pargal (2003). This explores the determinants of private investment in electricity in 9 Latin American countries along with private investment in various other infrastructure industries (roads, railways, water and telecoms).

\subsubsection{Bergara, Henisz and Spiller (1998)}

The stated intention of this paper (henceforth BHS) is to explain the role of different countries institutional endowments on their electricity utilities' investment decisions $^{41}$. As the title of the paper suggests, the focus is on political institutions and risk, including the legal system. However, the dependent variable in the BHS regressions is total generating capacity $(M W)$ per thousand population for some year (unstated) presumably in the mid-late 1990s rather than investment.

The independent variables include a few simple economic control factors - per capita GDP, industrial output as a share of GDP, urbanisation and the share of hydrogeneration.

Following Levy and Spiller, the BHS emphasis is on political and legal institutions rather than regulatory agencies. Indeed, the latter are not included in the data set. The major problem for the analysis was that the individual political and legal variables were highly correlated with one another so that it was necessary to include a set of political variables as an index variable. Hence, BHS constructed two weighted average composite variables which were used in a regression on a sample of 86-87 countries. However, for a sub-sample of 38 countries, BHS had data on judicial tenure. They claim that this had the same explanatory power and magnitude as the other variables.

The overall BHS result was that increasing the degree of political commitment (as measured by their indices) of a middling score DTE by one standard deviation would be expected to raise the level of generating capacity by $1.2 \mathrm{MW}$ per 1000 population a $49 \%$ elasticity at the mean. ${ }^{42}$

$41 \quad$ Bergara, Henisz and Spiller op cit, p 20
$42 \quad$ See BHS op cit, pp 23-25. 
These results are interesting but very preliminary. Regulatory institutions per se are not considered explicitly in the modelling. The simple cross-section framework militates against any real attempt at analysing causation and (as BHS recognize) is bedevilled by problems of multi-collinearity. Nevertheless, the significance of judicial tenure (as a \% of US judicial tenure) corresponds interestingly to the ICB literature where, for developing countries, the turnover rate of central bank governors dominates the formal legal attributes of the ICBs - unlike developed countries where the opposite is the case. Hence, for developing countries, the BHS regression results provide some supporting evidence for the conjecture that, for good performance on output measures, the reliability of the legal system in practice is more important than the formal properties as written on paper.

\subsubsection{Zhang, Kirkpatrick and Parker (2002)}

This paper (henceforth ZKP) explores the roles of competition, privatization and regulation in 51 countries in Africa, Latin America, the Caribbean and Asia on:

Net electricity generation per capita

$>$ Installed generation per capita (ie the BHS proxy for investment)

$>$ Net electricity generation per employee (ie labour productivity)

$>$ Generation relative to average capacity (ie capacity utilization)

$>$ Final prices to consumers.

The empirical work uses data for 1985-2000 and applies a fixed-effects panel data estimation technique as in the similar studies that have been carried out for telecoms.

The objectives of the paper and its methodology are all good practice, particularly over specifying the hypotheses to be tested. Besides the institutional variables, the regressions include standard control variables e.g. per capita GDP, share of industry output in GDP and an urbanization indicator. The problem is that the data for the key institutional independent variables are, as the authors recognize, low powered and poor quality proxy variables for the underlying effects that they wish to test.

The precise definitions of the variables are as follow:

(i) Privatization

Countries are given a score of 1 if there is any private sector generation and zero otherwise. This is much more a measure of private participation than of privatization. On the basis used, India would presumably count as a "privatized" country just as much as Chile.

(ii) Competition

Countries are given a score of 1 either if there is a wholesale generation market and/or if large users negotiate contracts directly with generators. This is more directly relevant than (i) but again, as the authors recognize, it would classify a system with a heavily dominant incumbent and one or two IPPs selling to industrial firms (e.g. Jamaica) as a competitive market.

(iii) Regulation 
Countries are given a score of 1 if there is a separate regulatory agency "not directly under the control of a ministry ${ }^{43}$." Presumably this is not formally (ie in legal terms) under the control of a ministry rather than any measure of control in practice. Following Wallsten, the authors suggest that this variable should be considered “as indicating a country's propensity to undertake regulatory reform rather than being a precise indicator of the operation of a separate regulator. ${ }^{44,}$ Unfortunately, when discussing the results of the regressions, the text of the paper treats the variable as if it were measuring the effectiveness of independent regulation on the outcomes listed above rather than in the much more modest terms used when describing the data.

One other fundamental problem with using the ZKP measures (i)-(iii) is that there is no date for the change and the regulatory dummy variable is not dated. Hence, a country like Ethiopia establishing a non-Ministry regulator in 1999 scores 1 for the whole of the estimation period - as would Costa Rica, which did so in 1928. The same problems arise with the other variables. Hence, there is no distinction in the estimation between the many DTEs who made these changes in the mid-late 1990s from those who did so rather earlier. This is a serious weakness in a data set for 19852000 .

The same problem arises with the privatization and competition dummy variables where, again, a change in the last 1-2 years of the period is ascribed to the whole of the estimation period. Data problems may have forced this approach but it does mean that most of the panel data potential is inevitably lost because the dates of the changes are not utilized.

The regulation variable is not a significant, correctly signed explanatory variable in any of the regressions reported. It is significant at the 5\% level but negative in the capacity utilization equation. Otherwise, coefficients on the regulation dummy are frequently positive but with t-statistics more often than not less than 1 . The regulatory variable is significant and positive at the $5 \%$ or $10 \%$ level when interacted with the "privatization" variable in the generation, capacity and productivity equations The interpretation of this result is difficult, however ${ }^{45}$. Curiously, regulation when interacted with the competition dummy is estimated to have a significant (at the $1 \%$ level) positive effect on electricity prices to industry. This is highly counter-intuitive and may well result from data problems (e.g. from jumps in reported home country prices following major exchange rate changes).

The competition dummy performs rather better than ether of the other two dummies at least in the generation, capacity and productivity equations. However, it is a markedly better proxy than the regulation and privatization dummies.

The results in the reported regressions are interesting and stimulating but very preliminary. The problem is that the data used for the key variables provide such poor proxies. This is the case for investment and, especially, for the regulation and privatization variables. Hence, the ZKP interpretation of their results for policy purposes cannot be sustained with this information set. It needs much better data than

\begin{tabular}{ll}
\hline 43 & See ZKP op cit, p.12. \\
44 & See ZKP op cit, p.13. \\
45 & See ZKP op cit, pp 16-17.
\end{tabular}


they were able to assemble. The approach taken can, however, provide a useful starting point for further work using a better data set, particularly for regulation.

\subsubsection{Pargal (2003)}

The Pargal paper discusses private investment in five infrastructure industries in nine major Latin American countries between 1980 and 1998. The strength of the Pargal study is that the data available to her are significantly better than for the previous studies in providing numerical indicators of the key variables at issue. In addition, the data allow her to put dates on major changes that enable much more powerful use of panel data estimation. Even so, the variables on regulation and liberalization are still far from ideal and cause problems in interpreting some of the regression results. Nevertheless, this paper provides much the best study as yet for the effect of independent regulation on electricity industry outcomes - at least for Latin America.

The study combines the high quality Calderon-Easterly data set on Latin American infrastructure investment (public and private) with regulatory variables derived from the Guasch data set on Latin American concession contracts. Since the dates of legislation liberalizing the sector and establishing the regulator are known, each sector can be given a dummy of zero for the years before the change and one thereafter rather than a simple time-invariant zero-one dummy. Standard control variables relevant to an investment equation are also included (eg real GDP, lagged capital stock and real interest rates).

Although the data on regulation and other institutional features is far superior to the BHS and ZKP studies, there are still significant problems in establishing a robust estimate of the effects of regulation (and key governance features. These are general issues but we will concentrate here on the implications for the power sector:

(i) As Pargal recognizes, liberalization in the power sector was usually accompanied by restructuring of vertically integrated utilities ${ }^{46}$. Indeed, the same law would almost always establish the regulatory agency. Hence, separating the effects of regulation from liberalization is extremely difficult when both are dated by the enactment of a reform law. (Note that this is more likely to be a problem for electricity than for telecoms for which a number of countries have partially liberalized before introducing a regulator ${ }^{47}$.)

(ii) The regulatory variables are all taken from the legislation. There are no data on the informal aspects of regulation - how the regulatory system operated in practice.

(iii) There are no data on the degree of liberalization and the amount of competition in practice (e.g. measures of concentration).

$46 \quad$ See Pargal, op cit p.15.

For Pargal's 9 country sample, 6 countries had an electricity regulator and allowed private entry. Of the 6 , the gap between the date of allowing entry and the date of establishment of the regulator was 1 year in 3 cases (Brazil, Colombia and Peru), 2 or 3 years in 2 cases (Argentina and Ecuador) and 7 years in the last case (Chile) - where the regulator is by no means fully independent. (S Pargal: Private communication, July 2003). 
(iv) The investment data only exist up to 1998 which is before the major recent downturn. An obvious issue is whether countries with better regulatory frameworks have had a smaller fall in private investment following the post1999 downturns.

Pargal reports estimates from two fixed effect regressions to explain the determinants of private investment levels. The equations are pooled across all 5 sectors and all 9 countries in her sample. The first set of estimates covers all years and the relevant regulatory variable is a simple $0 / 1$ dummy for each sector, country or year on whether or not a regulator existed (in legal terms).

The second set of estimates reports the effect of a variety of 5 major regulatory governance features:

1) Regulator inside or Outside the Ministry

2) Appointment of Regulatory Commissioners by Executive alone or with involvement of Legislature

3) Number of regulatory commissioners (Note not regulatory staff numbers.)

4) Regulator funded by central government

5) Rate or return or price cap regulation.

The equations are estimated on the pooled sample but only for the years after the regulatory body for the country and sector was (legally) established.

Finally, regressions for the 9 countries with the single regulatory variable were estimated separately for private investment in each of the five sectors.

The main result is that the variable for legislation to open up the sector consistently dominated the regulatory variables. This is true both for the pooled regressions and the individual sector (including the electricity industry) regressions. Indeed, the simple regulatory variable never had a t-value greater than 1 . The question is whether or not this is a robust finding.

We have pointed out above that the ascription of the relative effects of regulation and liberalisation is very difficult - particularly if they are both measured by legislative indicators and the change was in the same law. This is confirmed empirically. Pargal notes in a footnote that the coefficient on the regulatory variable had higher t-values when the liberalisation variable was omitted ${ }^{48}$. Unfortunately, we are not told the results of that regression nor is there any discussion of this issue in the regressions by sector. In addition, we note that the estimates of the regulatory variables may be downwards biased because of the errors-in-variables from the (unavoidable) absence of any data on regulatory practice.

The results for the individual regulatory variables in the pooled regressions are also strange and, in some cases counter-intuitive. Only the coefficients on 1),2) and 4) are significant at the $10 \%$ level or above. The coefficient on funding is significant at the $5 \%$ level and the right sign (ie licence fee funding is associated with higher private investment, presumably because this increases the effectiveness of the regulatory

$48 \quad$ See Pargal, op cit, footnote 7, p.17. 
agency). However, the coefficient on having a Ministry regulator is significant at the $5 \%$ level and the wrong sign (ie a Ministry regulator is positively associated with higher private investment and an independent regulator negatively associated.) Pargal puts forward some ingenious arguments why this might be so but we do not find them convincing and they are, in any event, inconsistent with the funding result.

Pargal's paper takes the estimation of the impact of regulation on outcomes in the power sector rather further forward but this paper still raises at least as many questions as it resolves. That seems to arise primarily because of the problem of having to rely exclusively on data drawn from the characteristics of reform legislation rather than from subsequent observed practice.

The main lesson to be drawn from the analysis seems to be that only when data which include regulatory experience and the amount of actual competition will it be seriously possible to try to disentangle the effects of regulation - and individual regulatory governance characteristics - in a regression analysis approach.

One other feature is that the availability of comparable cross-country data on investment in the electricity industry in DTEs seems to be confined to data on generation capacity. This seems to be the case even in the Calderon-Serven data set. This is most unfortunate given the emphasis (a) on transmission capacity for successful unbundling and (b) on the role of distribution for electricity reform in DTEs.

\subsection{Empirical Studies of the Impact of Regulatory Agencies on Telecommunications Outcomes in DTEs}

There is a rather larger literature on the impact of regulation on telecom outcomes than on electricity outcomes. This is, not least, because there are more countries with independent regulatory agencies which have 5 years or more of existence (at least of legal existence $)^{49}$. However, because this paper is primarily concerned with electricity outcomes, we will concentrate on three of the most recent and relevant papers - Fink, Mattoo and Rathindran (2003), Wallsten (2002) and Gutierrez (2003). In addition, we will concentrate on the parts of those papers concerned with estimating the effects of regulation on (a) mainline penetration rates (a measure of capacity growth) and (b) efficiency (eg mainlines per employee).

\subsubsection{Fink, Mattoo and Rathindran (2003)}

This paper benefits from being able to use the ITU-World Bank Database on telecommunications policy. This has been supplemented by data from the Stanford World Bank database (for Latin America) and data from the World Bank African Telecommunications Research Project. This is a much more comprehensive data set than has so far been collected for electricity. In particular, the data allow for the dating of policy changes and hence the use of time-based dummies for different policy changes and the exploration of optimal sequencing.

$49 \quad$ See Wallsten (2002), Table 1 
There are, however, difficulties in using the results of the paper to make reliable inferences on the effects of regulation. The key problems are two-fold:

(i) As recognized by Fink et al, the regulatory variable is a simple, timedated $0 / 1$ dummy as to whether or not a country has an autonomous regulatory agency; and

(ii) The exploration of sequencing concentrates on whether or not the introduction of competition preceded privatization. The date of establishment of the regulator relative to the introduction of competition and privatization was, with one exception, not explored.

Indeed, the reported results only consider the impact of regulation as to whether it increased the effects of competition and privatization i.e. as interactive terms. In addition, counties without an autonomous regulator were excluded from these equations so that there are no estimates estimating the effects of regulation on countries for countries with and without a regulator.

The equations estimated are fixed effect models on a panel of 86 non-OECD countries for the period 1985-99 but for the equations involving regulatory variables, the panel was reduced to those countries with a regulator - about 70 . The estimation technique used was Kmenta's CHTA variant of feasible generalised least squares (FGLS) ${ }^{50}$. The equations include standard control variables, primarily a time trend, population and per capita GDP.

Bearing these qualifications in mind, the estimation results are nevertheless supportive of a positive impact of regulation on investment and efficiency. The key results are ${ }^{51}$ :

$>$ The coefficients on the competition-regulation variable and the privatizationregulation variable are both positive and significant at the $1 \%$ level for both mainline penetration and labour productivity.

$>$ The estimated coefficients on the competition-regulation variables are larger than the coefficient on competition alone both for mainline penetration and labour productivity, but the estimated coefficients on the privatizationregulation interaction term are, in both cases, lower than the coefficient on privatisation alone $\mathrm{s}^{52}$. (The results come from different groups of countries and so cannot be formally compared).

$>$ Full reform (i.e. competition plus privatization and regulation) is also significant at the $1 \%$ level - years of full reform are associated with $8 \%$ higher mainline penetration and $21 \%$ higher productivity than years of no or partial reform.

$>$ The presence of an independent regulator (legally established prior to the introduction of competition and to privatization) again increases the impacts of privatization and competition - particularly the latter.

$50 \quad$ See Fink et al Appendix 4 for a discussion of estimation issues and a justification for their choice of estimation technique.

51 See Fink et al op cit, pp 13-17 and Tables 1-4.

52 The competition dummy is set to 1 for countries with any competition in local fixed line services and the privatisation dummy is et to 1 where the incumbent telecom company has been partially or wholly privatised.. 


\subsubsection{Wallsten (2002)}

Wallsten (2002) concentrates more on regulation per se. The concern of this paper is whether or not the establishment of a regulator before privatization (defined as partial or total sale of shares of the incumbent telecom company) provided benefits in terms of higher investment and larger privatisation revenues.

Like Fink et al, the paper estimates fixed effects models on a data set of 200 countries over the period 1985-99. The models estimated date the establishment of the regulator using ITU data - many were only established after 1995. Unlike Fink et al or Pargal, there are no data on competition or liberalization so that the effects of privatization and regulation may be exaggerated.

One other feature of the Wallsten data is that the sample included major OECD countries (including the US, the UK, France, Germany, etc) and there are no estimates reported for developing countries only and there are no dummies for international regions. Hence, the results reported may be unreliable to the extent that different factors are relevant (or more important) in rich than in poor countries (e.g. on quality of regulation $)^{53}$. The estimated equations included the standard control variables of per capita GDP and population.

One interesting feature is the use of self-reported answers on whether regulators were independent. The specific question to which countries sent replies to the ITU was whether "the Regulatory Authority [is] independent from political power" 54 . As Wallsten points out, this is a very ambiguous question with clear incentives to provide an answer of independence - and virtually no penalties against providing such an answer. Wallsten rightly points outs that this is emphatically not an appropriate way to collect reliable data on the quality of regulation ${ }^{55}$.

Bearing these qualifications in mind, the estimation results are nevertheless supportive of a positive impact of regulation on investment. The key results are:

For the full sample of 185 or more countries, a separate regulator is positively associated with the number of cellular subscribers but not investment in fixed services. (This could well be a liberalization effect if competition - and competition in mobile services - were introduced at the same time or soon after the establishment of the regulator).

$>$ Installing a regulator before privatization is positively and significantly associated with investment - mainlines, mainlines per capita, telecom investment (almost entirely investment by incumbents) and number of mobile subscribers.

$>$ The problematic "regulatory independence" variable was negatively associated with the investment variables, sometimes significantly so.

For the 33 countries which had partially or wholly privatised their incumbent telephone company, having a regulator in place before privatization was

\footnotetext{
53 DPS (2002) found that different equations between developed and developing countries were crucial for understanding regulatory staff numbers.

See Wallsten op cit, p 10.

See Wallsten op cit p 10-11.
} 
positively and significantly associated with the implied privatization sales value.

In an earlier 1999 paper, Wallsten estimated non-sequentialized models for 30 Latin American and African countries. The effect of having a regulator was never significant at the $5 \%$ level or better for any of the telecom indicators. However, a variable interacting privatization and regulation was positive and significant for mainline penetration, number of payphones and amount of connection capacity. This model included a variable intended to capture competition in fixed line services. However, the proxy - the number of wireless operators owned by a company other than the incumbent - is a relatively poor one.

\subsubsection{Gutierrez (2003)}

Gutierrez (2003) concentrates on estimating the impact of regulation on telecom outcomes in 22 Latin American and Caribbean countries. As with the other telecom papers discussed above, he uses panel data techniques which he applies to the experience over the period 1980-1997.

The main importance of this paper is that:

(a) the regulatory variables used are an index (or sub-indices) derived from a number of characteristics of regulatory governance;

(b) it reports tests for endogeneity of competition, privatization and regulation; and

(c) it reports results for static and dynamic panel models as well as testing for fixed versus random effects

The index used in this paper is a 7-item index with each element being given a $16.7 \%$ weight. The index is made up entirely of legally defined measures. There are no items on regulatory practice (e.g. turnover of regulatory commissioners) or quality, not least because of the problems of collecting such data for other than a very small sub-sample of countries.

The measures in the index are:

1) A Legal factor - whether the telecom regulator (for countries where an independent regulator is present) was established by a primary law or a decree;

2) A Separation factor - whether operating and regulatory factors were separated, irrespective of whether the regulatory activities were carried out by an autonomous regulator; and

3) A group of 5 factors labelled "ITU/Ten" incorporating issues of autonomy, accountability and clarity of roles. These last were factors generally identified with good regulatory practice identifiable from legal and related documents.

The specific factors included in 3) were:

○ Autonomy - measured (i) by budgetary independence and (ii) by legal limits on government freedom to replace regulators; 
- Accountability - measured by the existence of dispute resolution mechanisms to address disputes between the regulator and operators (ie an appeals mechanism);

- Clarity of roles - in terms of the regulator's ability (i) to set tariffs and (ii) to fine or penalise operators; and

○ Transparency and participation in the regulatory process.

Gutierrez (2002) sheds much more light on the index and its construction and also slightly extends the index to 8 factors, each with $12.5 \%$ weight. This paper also makes it clear how the intention is to operationalize the typology of Stern and Holder (1999) - at least for de jure characteristics. The factors reported are those as above but with the inclusion of a dispute resolution capability between telecom companies. The transparency and participation variable is defined as the mandatory use of public hearings for tariff setting and other issues.

An important feature of the index is that it changes over time as new legal developments take place. Gutierrez averages the changes by taking 5 or 10 year averages. Almost all the changes are increases in the values of the index ${ }^{56}$.

The construction of this index by Gutierrez is a major advance on previous attempts to measure the components of regulatory governance in a systematic and comparable manner. It is possible to take issue with some of the components - the use of public hearings as a proxy for transparency and participation is a very American-centric view and (we would argue) a less good proxy than a requirement for the regulator to publish the reasons for decisions. We would also argue that reliance on formal legal indicators alone misses key elements, however understandable it is on practical grounds. Indeed, it is difficult to see how much further one could go in constructing an index in the absence of systematic and comparable case studies of countries experience. The fact that the earlier ( 7 factor) version of the index was consistently important in explaining changes in telecom outcomes when used in the econometric work demonstrates the returns from the effort involved in its construction.

The equations estimated include as control variables: per capita GDP, the trade intensity of the country and population density.

The main results from the econometric work were as follows:

$>$ For the full 22 country Latin American and Caribbean sample, the regulatory index was consistently significant at the $1 \%$ level. A 1-point increase in the index was, in the static model panel model, associated with a $5-25 \%$ increase in the number of main lines per 100 inhabitants; the dynamic model showed a 40-50\% larger response;

$>$ Estimation with the regulatory index included as a quadratic indicates diminishing returns to improvements in regulatory quality;

$>$ Separating the index into its three component elements shows that the elements generally have the predicted (positive) sign on tele-density and 
efficiency. They are also, in most cases, statistically significant at the 5\% level;

$>$ Privatisation (defined as at least $50 \%$ divestment) is consistently associated with higher tele-density. Interacting privatisation with regulation gives a large and highly significant interaction term; the coefficient on the regulatory index remains positive and significant but is reduced in size by about $40 \%$ while the coefficient on ownership falls and is no longer significant.

$>$ Competition (defined as competition either in fixed or in mobile services) has no general significant effect either on its own or when interacted with the regulatory index and, even when significant, has a relatively small coefficient estimate;

$>$ Allowing for the endogeneity of competition, privatisation and regulation make little difference to the coefficient estimates; fixed effect models dominate random effects models; dynamic models out-perform static models but the estimates are dominated by large lagged dependent variable coefficients and introduce additional estimation issues.

For a smaller sample of 12 lower income Latin American and Caribbean countries, the estimated regulatory coefficients are, more often than not, significant at the $5 \%$ level but rather smaller than for the 22 country sample. Conversely, the estimated effects of privatisation and competition are stronger than in the full sample. Gutierrez points out that, although this may reflect potentially greater difficulties in establishing effective regulatory agencies in low income countries, it may also reflect the fact that the regulatory agencies are, on average, younger in the low income sample.

The issue remains as to how far the index based on formal legal properties is a good proxy for the total effect of regulation, including variations in regulatory practice. The analysis in Section 2.4.1.3 above suggests that it may be a reasonably good proxy but that analysis is based on a data-set with limited - and perhaps (in hindsight) over-optimistic data on the performance of regulatory agencies. Hence, the question remains open.

\subsection{Conclusions from Econometric Modelling of the Impact of Regulation on Utility Industry Outcomes}

The key conclusions from this section are:

1) There is some evidence from recent econometric studies that the existence of an independent regulatory agency increases investment and productivity levels. The evidence is strongest for telecoms.

The recent telecom studies have had access to better data than the electricity studies. Even though none of the telecom studies have had information on regulatory practice, they have produced evidence of a positive effect either directly and/or by augmenting the effects of competition and privatisation. The strong positive results from the use of an index of regulatory characteristics in Gutierrez (2003) is particularly noteworthy. Thus far, for 
electricity, there are some preliminary indications of a positive effect of regulation but nothing conclusive.

2) It is often difficult to separate the effects of introducing an independent regulatory agency from the effects (a) of liberalisation/introducing competition and (b) of privatisation.

The introduction of a regulator is often done in the same law as liberalisation, restructuring (where carried out) and privatisation. Hence, it is difficult to disentangle the relevant effects - particularly for recently established regulators and in the absence of data on regulatory performance. This is likely to be a more serious issue for electricity than for telecoms.

3) The econometric analysis of the impact of regulation has not yet been able to address the issue of errors-in-variables from the absence of data on regulatory practice/performance.

4) Concerns have been raised as to the potential endogeneity of regulation (as well as of competition and privatisation. Gutierrez (2003) has addressed this problem; but, as yet, there is no evidence that endogeneity is an important problem in practice. For telecoms, correcting for endogeneity has little effect on coefficient estimates.

5) Thus far, the econometric analysis has concentrated on estimating panel data models, mainly static models but with some use of dynamic models. There is room for attempting alternative approaches including the use of frontier analysis.

6) For electricity, there is an urgent need for data on investment in transmission and distribution to supplement the available data on capacity growth in generation. 


\section{Independent Central Bank Governance, its Measurement and its Impact on Macro-economic Outcomes}

Over the last 20 years, there has been a huge literature on how independent central banks (ICBs) can be used to address the time inconsistency problem in macro-policy and inflation control that governments inevitably face. This literature goes back to the seminal articles by Barro and Gordon in 1983 and Rogoff (1985). In recent years, there has been some recognition that the time inconsistency problem faced by governments with regard to inflation is essentially the same as the one they face with regard to private investment in utilities ${ }^{57}$.

In both cases, the standard solution to the problem is to institute an independent agency - an independent central bank in the macro-economic case and an independent regulatory agency in the utilities case. Interestingly, it is recognised in both literatures that contracts can (at least in theory) substitute for an independent agency. More importantly, in both literatures, the questions loom large (a) of the degree of discretion of the agency and (b) the role of government in setting policy objectives, giving policy direction, etc.

In both literatures, having an independent agency seems to be crucial in combining credibility with the ability to respond to new developments with discretion rather than having to follow an inflexible pre-determined rule. In macro-economic policy, the rigid monetary growth rules of the 1980s proved disappointing and a zero discretion regime for utility regulation has also proved very difficult if not impossible to sustain in the medium to long-term. Hence, the search for bounded, accountable discretion has been common to macro-economic policy and utility regulation and this has led to a common focus on the key governance aspects that will enable this to be sustained.

From this perspective, effective governance of an independent agency is seen as the way to achieve lower and less variable inflation in the macro-economic case (as well as, hopefully, lower average unemployment and higher growth rates) and to bring higher average levels of (and/or lower cost) investment in the utility regulation case ${ }^{58}$. A well-designed ICB, often with an inflation target, is the mainstream recommended solution to the macro-economic commitment problem in the same way that a welldesigned regulatory agency is the conventionally recommended solution to the utility investment commitment problem. However, in both cases, it can be hard to sustain the institutions and their independence in difficult political environments

There has been a huge literature on the macro-economic time inconsistency problem and a very large one on ICBs, their design and effectiveness. In this paper, we will concentrate on a few key points, drawing very largely on two major recent surveys: Berger, de Haan and Eijffinger (2000) and Geraats (2002). We will also concentrate on the evidence concerning developing countries not least because the commitment problem in DTEs is more acute than for developed countries and the empirical work on the determinants of ICB effectiveness addresses this issue directly.

\footnotetext{
$57 \quad$ See Stern and Trillas (2002) for an informal discussion and comparison and Levine, Stern and Trillas (2003) for a formal model as well as references to earlier papers.

58 See Brown (2001) for a fine exposition of the macro-economic governance issues, Newbery (1999) Chapter 2 for a discussion of the utility regulation design issues, Stern and Trillas (2002) and Levine, Stern and Trillas (2003) for a discussion of the joint issues.
} 


\subsection{Governance Issues for ICBs and Independent Utility Regulatory Agencies}

Much of the literature on ICG governance concentrates on similar issues to those discussed in the utility regulation literature eg quality of laws, appointment and dismissal criteria for ICB governors, etc. There has also been some explicit investigation of the role of transparency. This is true both in the narrow sense (ie the impact of ICBs providing justification for their interest rate decisions) and in a wider sense.

For the wider sense of "transparency", Geraats (2003) - following Eijffinger and Geraats (2002) and their survey of nine formally independent OECD central banks identifies five different elements of transparency.

These are defined as follows:

Eijffinger and Geraats (2002): Central Bank Transparency

1. Political Transparency - Openness about policy objectives

Formal objectives for monetary policy

$>$ Quantification of primary objective(s)

$>$ Explicit contractual arrangements or contracts between monetary authorities and central bank

2. Economic Transparency - Economic information used

$>$ Availability of basic economic data

$>$ Disclosure of formal macroeconomic models used for policy analysis

$>$ Publication of central bank macroeconomic forecasts

3. Procedural Transparency - The way monetary policy decisions are taken

$>$ Explicit policy rule or strategy

$>$ Comprehensive and timely explanation of policy decisions

$>$ Disclosure of voting behaviour

4. Policy Transparency - Disclosure and explanations of decisions

$>$ Prompt announcement of decisions

$>$ Explanation to accompany announcement

$>$ Future policy inclination

5. Operational Transparency - Implementation and evaluation of policy

Frequent evaluation of extent to which policy targets are met

$>$ Regular provision of information on unanticipated disturbances

$>$ Regular evaluation of policy outcomes in light of objectives. 
There is a strong correspondence between several of these and the 6-element SternHolder list of attributes of effective regulatory governance discussed in Section XX above. In particular, there is a strong correspondence between:

o the Eijffinger-Geraats concept of Political Transparency and the SternHolder concept of Clarity of Rules and Objectives; and

$\bigcirc$ the Eijffinger-Geraats concept of Procedural Transparency and the Stern-Holder concept of Participation;

○ the Eijffinger-Geraats concept of Policy Transparency and the SternHolder concept of Transparency per se.

There is also some similarity between the Eijffinger-Geraats concept of Operational Transparency and the Stern-Holder concept of Predictability. (The similarity would be closer if the SH concept were expanded to include regular evaluation of performance and functions to be regulated.) Probably the most interesting difference is that there is no equivalent in the Stern-Holder list to the Eijffinger-Geraats concept of Economic Transparency - public availability of relevant economic data and models. The latter is only likely to be feasible where the regulator is making decisions on a set of firms (eg a group of national electricity distribution companies or water companies) rather than a monopoly suppler or dominant incumbent ${ }^{59}$.

The Eijffinger-Geraats conceptualisation is not unique. Indeed, it usefully synthesises a number of theoretical and empirical studies of ICB governance and ICB effectiveness over the last 20 years. Given that studies of ICB effectiveness have shown a positive effect of better governance on macro-economic outcomes, this strongly suggests that tests of regulatory effectiveness can draw on this literature.

Two particularly interesting observations in this context are:

(i) Few countries develop independent utility regulatory institutions that do not already have an independent central bank; and

(ii) Countries that have difficulties in sustaining an effective ICB also have difficulties in sustaining effective utility regulatory agencies (eg Argentina, Bulgaria).

These observations demonstrate the relationship between the ICB and regulatory effectiveness issues with the wider question of the role of institutions in promoting and sustaining good policies and strong growth. Much attention has been given in recent years to this wider issue eg in Rodrik (2003) and many of the papers referenced there.

The observations above also strongly raise the issue of what can reasonably be expected from regulatory agencies in difficult environments where the rule of law and civil society institutions are weak and corruption may be pervasive. On the narrower

$59 \quad$ See Stern (2002) Mimeo for a slightly fuller discussion of the similarities and differences between the two sets of governance concepts. 
issue of tests of regulatory (or ICB) effectiveness, it raises the question as to the appropriate set of controls for these wider country-specific concerns.

\subsection{Empirical Evidence on ICB Effectiveness and Governance Measures}

The recent survey article by Berger, de Haan and Eijffinger provides a good overview. For our purposes the key results that emerge are:

1) ICBs are associated with lower average inflation rates but not with higher growth rates. The inflation result is robust to measures of inflation aversion.

2) For OECD countries, the ICB indicator associated with lower inflation is a measure (eg an index) of formal legal characteristics. The relationship appears to be "quite robust" "60.

3) For developing countries (low and middle income) as a whole, legal ICB indicators have little or no explanatory power whereas practice is significant and correctly signed. The typical measure of ICB (and government) practice is the turnover rate of Central Bank governors (eg the probability that governors will be replaced within a short time of a change in government $)^{61}$.

4) Some recent work suggests that the effect of the turnover rate of $\mathrm{CB}$ governors on developing country inflation rates is only significant if high inflation countries are included. Sturm and De Haan (1999) find that excluding these observations leads to significance of coefficients on the legal indicators.

The evidence suggests that ICBs do affect the inflation rates and that the quality of their governance matters. However, the relevant measure of quality seems to vary between OECD and developing countries. For OECD countries, the government and other parties involved appear to follow the "rules of the game" as set out in the relevant law and supporting regulations. For developing countries, particularly developing countries with political instability involving radical changes of government, the relevant measure of quality seems to be how far the law is observed in practice and in spirit - hence, the importance of turnover rates for ICB governors.

In the context of utility regulation, these results support the need to have data on regulatory practice as well as on the quality of regulatory legislation. It may also be worth pursuing the idea of collecting measures of regulatory commissioner (or office head) turnover - for instance, the proportion of commissioners (or office heads) whose term ends prematurely. This may be a good first-attempt proxy for indicators of regulatory practice.

\subsection{ICB Transparency}

ICB transparency (in the narrow sense of transparency ie how far central banks strive to explain their actions) is an area where empirical studies have only recently started, not least because it is a relatively recent development.

$60 \quad$ See Berger et al, op cit, p.29.

61 This result, first established in Cukierman (1992) and discussed in detail in Cukierman and Webb (1995), has been replicated in a number of other studies. 
Empirical work has concentrated to date on two themes:

(i) The impact of ICB transparency on financial market responses eg the degree to which interest changes have become more predictable; and

(ii) The impact of greater transparency on macro-economic outcomes.

For much of this work, the measures of transparency used have been taken from Fry et al (2000) or subsequent developments. The types of variable included in the transparency index are whether or not the CB provides

Explanations of policy decisions - how closely they are announced relative to the decision being made, the publication of minutes and voting patterns, etc

> Published forward looking analyses - the role of forward-looking analysis of economic developments, the clarity of inflation forecasts, the publication of inflation forecasts, published risk assessments and discussion of past forecasting errors, etc.

The frequency of published assessments of economic developments whether they are published monthly, quarterly or less frequently.

\subsubsection{The Impact of ICB Transparency on Financial Market Responses}

The main findings to date are as follows:

(i) Geraats (2002) reports that several studies have shown that greater information disclosure by ICBs is associated with a decline in the response of market interest rates to changes in the official interest rate. This has been found for Canada, the UK and the US ${ }^{62}$.

In the UK-US study cited, the main decrease is at the short end of the yield curve on interest rates, indicating that greater transparency on information has reduced information asymmetries about the economy.

(ii) For 18 inflation targeting central banks, Fracasso, Genberg and Wyplosz (2003) estimate that higher quality inflation reports (quality as measured by graduate student appraisals) are associated with smaller interest rate surprises. This is cet par, after including control variables on the country levels of inflation and interest rates as well as market and inflation volatility.

Quality is judged on 5 indicators, each based on a 1-10 scale:

a) How convincing the inflation report was;

b) How well the expertise of the bank came through;

c) How complete the report was;

62 See Geraats op cit, p. F558-9 and the references cited by her - specifically the studies (a) by Muller and Zelmer and (b) by Haldane and Read . 
d) The clarity of the writing style of the report - ie how well the report conveyed its message; and

e) The amount of information in the report.

An index averaging the five variables a) - e) was statistically significant at the $95 \%$ level with a t-value of 2.46 . The coefficient estimate implied an increase in the combined quality rating from 5 to 7.5 is associated with a reduction in interest-rate surprises of 13 basis points and an increase from 7.5 to 10 (the maximum possible) of an additional 7 basis points ${ }^{63}$.

$>$ The quality indices a) - e) were highly correlated with one another so that it was not possible to include more than one characteristic simultaneously in the equation. However, they could be included individually. All were correctly signed and significant at the $90 \%$ level or better.

Very interestingly, the indicator with the highest t-value (5.1) was the style variable - ie how clearly the report conveyed its message. The expertise variable had a t-value of 2.3 and the convincingness variable a t-value of 2.1.

Some highly ranked ICBs on the quality of their reports were relatively poorly ranked in terms of inflation surprises. This was particularly noticeable for Chile and Thailand. This suggests that it may take longer for developing countries to establish the credibility of their ICBs than for major developed countries ${ }^{64}$.

\subsubsection{The Impact of ICB Transparency on Macro-economic Outcomes}

As yet, there are relatively few studies of this. However, Geraats op cit finds examples of several which suggest that greater transparency in information improves macro-economic performance ${ }^{65}$. Findings to date include

(a) For an 87 country sample, increased information transparency is associated with lower average inflation rates (at least for countries without an exchange rate peg - where the issue is much less relevant. This result is cet par on a number of macro-economic and institutional variables.); and

(b) For a 63 country sample, increased information transparency is associated with lower variability of an inflation-output index.

Both the studies cited use the Fry et al index to measure information transparency.

63 See Fracasso, Genberg and Wyplosz (2003), p.33 and Table 4.2.

64 See discussion by Fracasso, Genberg and Wyplosz op cit, p36.

65 See Geraats op cit, p. F559 and her discussion of the studies (a) by Chortareas et al (2001) and (b) by Cecchetti and Krause. 


\subsection{Implications for Estimating the Impact of Utility Regulation from the ICB Governance Literature}

The key points that arise are as follows:

1) The experience with ICBs is useful for assessing the impact of independent utility regulatory agencies and is encouraging

There is a large literature with strong theoretical foundations as well as a sizeable empirical literature. The time inconsistency problem for inflation control and macro-economic policy credibility is formally very similar indeed to that of investment in utilities but it is easier to assess what are good and bad outcomes. Also the relevant measures of ICB governance (transparency) are very similar to those for utility regulation.

2) The literature on ICB effectiveness shows clearly that independent central banks are consistently associated with lower average rates of inflation and that the effects are larger with better governance.

The relevant measures of ICB effectiveness are different for OECD countries than for developing countries. For the former, it is the quality of the legal framework that is important whereas, for developing countries, the most relevant quality measure has been the turnover rate of ICB governors. This last is related to the vulnerability of governors to changes of regime and involuntary turnover in periods of political instability. However, some recent studies suggest that the quality of the legal framework may be more important in developing countries other than those with very high inflation rates with the turnover measure important only for the latter group.

3) Recent work on ICB information transparency shows that greater and more effective transparency is associated with fewer surprises (ie less uncertainty) in financial markets and there is some evidence that it is associated with better macro-economic outcomes.

This aspect again shows the practical importance of good practice by independent agencies in generating credibility and helping resolve the commitment problem.

In terms of further data collection and research on DTE utility regulators, the ICB literature points strongly towards the need for evidence on regulatory practice particularly on transparency and information exchanges. The ICB literature also suggests that a good first step for collecting information on DTE regulatory practice may be obtain data on premature departures from office by regulatory commissioners (or office heads). 


\section{Conclusions from the Literature Review}

According to Rodrik (2003), countries can have growth spurts of 10 years or more without having to invest in high quality institutions. But, he also concludes that to achieve sustained growth, there seems to be no alternative to the "acquisition of high quality institutions"

Regulatory institutions for utilities come into the growth sustaining category of economic institutions, as do independent central banks. Indeed, for utilities, there have been spurts in private investment without effective regulatory institutions - eg the Asian electricity IPP boom of the 1990s. However, as with the aggregate economy, it is difficult to see how sustained growth in utility service industry consumption, output, productivity and (in particular) investment can be achieved without the development of high quality regulatory institutions.

Rodrik (2003) discusses the results of much recent literature which argues - and estimates models that support the claim - that sound economic policies can only be sustained by high quality institutions. He is, however, anxious to show that the precise form of institutions can be expected to vary considerably ${ }^{67}$ provided the local variations embody key features. For utility service industries like electricity, there has been much argument but much less supporting evidence on this issue. In addition, there has been surprisingly little variation in the way that key governance features have been incorporated into different country designs.

The results of this literature review provide evidence that it is likely to be the case that soundly designed and well-established electricity and other utility service regulatory agencies should and do have a beneficial effect on industry outcomes.

We would expect this outcome to arise because regulatory agencies with better governance should (a) make fewer mistakes and (b) have their mistakes identified and rectified better and more quickly so that (c) good regulatory practice is more readily established and maintained. It may well be possible to obtain a major short-tomedium term increase in investment without an effective regulatory framework, but the considerations outlined above suggest that this will not be sustained long-term. The collapse of the Asian IPP boom of the early 1990s and the late 1990s difficulties with many of the Latin American infrastructure reforms and concession contracts provide some evidence to support this conjecture.

In terms of our review, the following points summarize why we might expect statistically significant effects of good regulatory governance on electricity industry outcomes in DTEs and more widely:

1) The literature on independent central banks which provide strong empirical and econometric support for the hypotheses (a) that countries possessing ICBs with better governance have better macro-economic outcomes and also (b) that greater ICB information transparency results in better outcomes.

\footnotetext{
$66 \quad$ Rodrik, op cit, p.24. He continues: "The growth-spurring strategies described above have to be complemented over time with a cumulative process of institution building to ensure that growth does not run out of steam and that the economy remains resilient to shocks." Rodrik uses the term "context-specificity". See Rodrik op cit p.27.
} 
Note that, for developing countries, the best indicator of ICB governance seems to be on ICB practice (usually measured by turnover of ICB governors) rather than on the quality of the legal framework - which is the best indicator for OECD countries. (See Section 2.5 for further discussion.)

2) Recent developments in the literature on telecommunications reform and regulation. This is increasingly showing that independent regulatory agencies are associated in developing countries with higher investment (eg mainline penetration rates) and faster productivity growth either directly and/or by augmenting the effects of liberalization/competition and privatization.

In this context, Gutierrez (2003) is important in demonstrating the contribution to effective estimation of the effects of regulation that can be made by using an index of regulatory indicators. (See Section 2.4 for further discussion.)

3) The results from studies of electricity and Latin American concession contracts provide some preliminary support for the effectiveness or regulatory agencies in promoting investment and/or preventing major concession contract problems.

The position is similar to that of investigating the effects of telecom regulation 3-4 years ago when developing country telecom regulators were, on average, still very young and when there was little purpose-designed data with which to test the impact of regulation on industry outcomes. For electricity, the lack of available and comparable data on investment in transmission and distribution is a significant problem.

Of course, having an effective regulator may be necessary but is by no means sufficient to generate sustained growth and this may help explain why the results have, so far, been a lot less than conclusive. Besides an effective regulatory agency, the following issues arise

- A well-designed industry structure is crucial - good regulation cannot overcome bad design of industry and market structures;

- The industry and the regulatory arrangements must be based within an effective governance framework - effective regulation cannot take root in corrupt systems or ones where the law courts are unreliable; and

- Commercialization has to be accepted as the basis of utility service provision, including pricing which avoids large scale implicit subsidy of prices to final users - the political economy of pricing reform has destroyed many utility reforms and new regulatory systems and threatens many more. This has been and remains a serious problem in electricity but seems to be worse in water and perhaps (passenger) railways. 
The first and third of these points may well be more important for the success of utility reform and independent regulation electricity than for telecoms - and more so again for water and railways.

However, in looking forward, we can identify some clear work priorities. These are:

a) The use of regulatory indices combining governance factors in future econometric and related statistical work.

We intend to follow up this conclusion in the estimates that we report for the impact of electricity regulation in our companion paper.

b) The need for better data, particularly on regulatory practice, showing the evolution of regulatory systems.

There is a great paucity of data on regulatory practices - snapshot data let alone successive observations. In addition, there is a clear errors-in-variables problem in the absence of data on regulatory practice. Our preliminary examination of this issue in the context of the Stern-Holder data set suggests that the problem is serious enough to cause concern but not sufficient to invalidate estimation of models using data on laws alone - at least until it can be supplemented by better data which will also greatly facilitate the testing of how much difference is made by not having data on regulatory practice.

c) Data on regulatory systems, their performance over time and their impact can be collected by informed researchers carrying out systematic and well-coded case studies.

This has been shown by the 1998 NERA study of regulation in six Asian developing countries and the Prayas Report. To provide well-based estimates of what works, why and what is most important requires such data to be combined with other industry and country data. These tasks are neither huge nor particularly novel in social research terms.

Rodrik and his co-authors, Easterly and Levine, Acemoglu and colleagues have all shown the returns from a similar kind of research structure to understand the roles of institutions and policy for aggregate growth. The task identified here is to do something similar for the institutions responsible for the growth of output and investment for electricity and other service utilities. 


\section{REFERENCES}

Acemoglu, D., Johnson, S. \& Robinson, J. A., (2000), "The colonial origins of comparative development: an empirical investigation" NBER Working Paper No. 7771 .

Bakovic, T., Tenenbaum, B. W. \& Woolf, F., (2003), "Regulation by contract: a new way to privatise electricity distribution", World Bank Energy \& Mining Sector Board Discussion Papers, no. 7.

Barro, R. S. \& Gordon, D.B., (1983), "Rules, discretion \& reputation in a model of monetary policy", Journal of Monetary Economics, Vol.12, pp. 1169 - 1189.

Bergara, M. E., Henisz, W. T. \& Spiller, P.T., (1998), "Political institutions and electric utility investment: a cross- nation analysis", California Management Review, pp. 18-35.

Berger, H., de Haan, J. \& Eijffinger, S.C.W., (2000), "Central Bank independence: an update of theory and evidence", Centre for Economic Policy Research Papers, DP No 2353.

Better Regulation Task Force, (2001), “Economic Regulators”, London, HMSO.

Brown, G., (2001), "The conditions for high and stable growth and employment." The Economic Journal, Vol. 111, No. 471, C.30-44.

Calderon, C. \& Serven, L., (2002) "The output cost of Latin America's infrastructure gap", The Macroeconomic Infrastructure in Latin America, Calderon, C., Easterley, W. \& Serven, L. (eds), The World Bank.

Calderon, C., Easterly, W. \& Serven, L., (2002), "How did Latin America's infrastructure fare in the era of macroeconomic crises?", Central Bank of Chile Working Papers, no.185

Cecchetti, S.G. \& Krause, S., (2002), “Central Bank structure, policy efficiency, and macroeconomic performance: exploring empirical relationships", Federal Reserve Bank of St Louis Review Vol. 84, No 4, pp 45-60.

Chortareas G. E., Stasavage, D. \& Sterne, G., (2001), "Does it pay to be transparent?: International evidence from Central Bank forecasts", Bank of England Working Paper Series, No. 143.

Cukierman, A., (1992), "Central Bank Strategy, Credibility \& Independence", Cambridge, MIT Press.

Cukierman, A. \& Webb, A., (1995), "Political influence on Central Bank International Evidence", The World Bank Economic Review, no. 9, pp. 397 - 423. 
Domah, P., Pollitt, M. \& Stern, J., (2002), "Modelling the costs of electricity regulation: evidence of human resource constraints in developing countries", London Business School Regulation Initiative Working Paper No. 49 and CMI Working Paper No.11.

Easterly, W. \& Levine, R., (2002), "Tropics, Germs \& Crops: how endowments influence economic development”, NBER Working Paper No. 9106.

Estache, A., (2002), “Argentina's Utilities Privatisation: A Cure or a Disease”, World Bank Institute, Mimeo Paper for WIP Conference in Berlin.

Fink, C., Mattoo, A. \& Rathindran, R., (2002), "An assessment of telecommunications reform in developing countries", World Bank Working Paper No. 2909.

Fracasso, A., Genberg, H. \& Wyplosz, C., (2003), "How do Central Banks Write? An evaluation of inflation targeting Central Banks", Geneva Reports on the World Economy and CEPR, Special Report No.2.

Fry, M., Julius, D., Mahadeva, L. Roger, S. and Sterne, G. "Key issues in the choice of monetary framework" in Monetary Policy Frameworks in a Global Context ed L Mahadeva and G Sterne, Routledge, London.

Geraats, P.M. \& Eijffinger, S.C.W., (2002), “How transparent are Central Banks?", Centre for Economic Policy Research Discussion Paper, No. 3188.

Geraats, P.M., (2002), “Central Bank Transparency”, The Economic Journal, Vol. 112 , no. 483, F532-65.

Gual, J. \& Trillas, F., (2002), "Telecommunications Policies: Determinants and Impact”, University of Barcelona, Mimeo.

Guasch, J.L., Laffont, J.J. \& Straub, S., (2003), "Renegotiation of concession contracts in Latin America", World Bank Working Paper No.3011.

Gutierrez, L.H., (2003), "The effect of endogenous regulation on telecommunications expansion and efficiency in Latin America", Journal of Regulatory Economics, Vol. 23:3 pp. $257-286$

Gutierrez, L. H., (2002), "Regulatory governance in the Latin American telecommunications sector", University del Rosario, Colombia and University of Florida Public Utility Research Center Working Paper.

Kennedy, D., (2003), "Power sector regulatory reform in transition economies: progress and lessons learned", European Bank for Reconstruction and Development Working Paper No. 78.

Kessides, I., (2004), "Reforming Infrastructure: Privatization, Regulation, and Competition", World Bank Policy Research Report. 
Lamech, R. and Saeed, K., (2003), "What international investors look for when investing in developing countries. Results from a survey of international investors in the power sector", The World Bank Group Energy and Mining Sector Board Discussion Paper No. 6.

Levine, P., Stern, J. \& Trillas F., (2002), "Independent utility regulators: lessons from monetary policy", London Business School Regulation Initiative Working Papers No. 52 .

Levy, B. \& Spiller, P.T., (1994), "The institutional foundations of regulatory commitment: a comparative analysis of telecommunications regulation", The Journal of Law, Economics \& Organisation, Vol. 10 pp.201-246.

Levy, B., (2002), "Patterns of governance in Africa", World Bank African Region Working Paper Series No. 36.

NERA, (1998), "Governance \& regulatory regimes for private sector infrastructure development", ADB RETA 5758 - REG, Asian Development Bank, Manila, Philippines.

Newbery, D. M., (1999), "Privatisation, Restructuring and Regulation of Network Utilities”, The MIT Press.

North, D. C., (1990), "Institutions, Institutional Change and Economics Performance”, Cambridge University Press.

Noll, R.G., (2000), Telecommunications Reform in Developing Countries", in Economic Policy Reform: The Second Stage ed. Anne Krueger, University of Chicago.

Pargal, S.: "Regulation \& private sector investment in infrastructure: Evidence from Latin America", April 2003, World Bank Policy Research Working Paper No. 3037.

Prayas Energy Group Report, (2003), "Performance of private electricity distribution utilities in India: need for in- depth review \& benchmarking", Prayas Occasional Report, Prayas Energy Group, Pune, India.

Rodrik, D., (2003), "Growth Strategies", John F Kennedy School of Government Working Paper, Harvard University, (Forthcoming in Handbook of Economic Growth).

Smith, W., (1997) "Utility Regulators - The independence debate", The World Bank Public Policy for the Private Sector Note No. 127.

Standard \& Poor's (2000), "Debt Rating Criteria for Energy, Industrial and Infrastructure Project Finance" by James Penrose and Peter Rigby in 2000-2001 Infrastructure Finance, October, pp 15-65.

Stern, J., (1997), “What makes an independent regulator independent?”, Business Strategy Review, Vol. 8, No. 2, pp 67-84. 
Stern, J. \& Holder, S., (1999) "Regulatory governance: criteria for assessing the performance of regulatory systems. An application to infrastructure industries in the developing countries of Asia", Utilities Policy, Vol. 8, pp.33-50.

Stern, J. (2000), “Electricity and telecommunication regulatory institutions in small and developing countries", Utilities Policy, Volume 9, pp 131-157.

Stern, J. (2000), "Styles of Regulation: The Choice of Approach to Utility Regulation in Central and Eastern Europe, LBS Regulation Initiative Discussion Paper No 34, and (revised version) in Utilities Reform in Europe, ed D Coen and M Thatcher, Nova Science Publishers, New York.

Stern, J. \& Trillas, F., (2001), "Regulation of telecoms: what works and why? Lessons from Independent Central Banks", Business Strategy Review, Vol 12, No. 4, pp 17-28.

Stern, J., (2002), Transparency and Accountability in Regulatory Agencies and Central Banks, London Business School, Mimeo.

Stern, J., (2002), "Regulation \& contracts for utility services: Substitutes or complements?", London Business School, Mimeo.

Stern, J., (2003), "Regulation \& contracts for utility services: Substitutes or complements? Lessons from UK historical experience", London Business School Regulation Initiative Working Paper No.54 and (revised version) Journal of Policy Reform (2004).

Stern, J. \& Trillas, F., (2003), "Independence and Discretion in Telecommunications Regulation. Lessons from Independent Central Banks" Utilities Policy, Forthcoming.

Stirton, L. \& Lodge, M., (2003), "Rethinking institutional endowment in Jamaica: Misguided theory, prophecy of doom or explanation for regulatory change?", CARR/ CRC/ ABS Risk Regulation, Accountability and Development Workshop, University of Manchester, June.

Subramanian, A., Rodrik, D. \& Trebbi, F., (2002) "Institutions rule: the primacy of institutions over geography and integration in economic development", NBER Working Paper No. 9305.

Wallsten, S., (1999), “An empirical analysis of competition, privatisation and regulation in telecommunication markets in Africa and Latin America", World Bank Working Paper No. 2136.

Wallsten, S., (2002), "Does sequencing matter? Regulation \& privatisation in telecommunication reform”, World Bank Working Paper No. 2817.

Williamson, O. \& Masten, S. (1999) “The economics of transaction costs”, Edward Elgar. 
Zhang, Y. F., Kirkpatrick, C. \& Parker, D., (2002), "Electricity sector reform in developing countries: an econometric assessment of the effects of privatisation competition and regulation", Centre for Regulation and Competition, Manchester CRC Working Paper No. 31. 